\title{
VIOLENCIA CONTRA LA MUJER, «CRÍMENES DE HONOR» Y PRÁCTICAS CULTURALES Y RELIGIOSAS PERJUDICIALES: ESTÁNDARES INTERNACIONALES DE DERECHOS HUMANOS ADOPTADOS POR LAS NACIONES UNIDAS
}

\author{
VIOLENCE AGAINST WOMAN, «HONOR CRIMES» AND \\ HARMFUL CULTURAL AND RELIGIOUS PRACTICES: \\ INTERNATIONAL HUMAN RIGHTS STANDARDS ADOPTED \\ BY THE UNITED NATIONS
}

\author{
María Nieves SALDAÑA \\ Universidad de Huelva
}

Recibido: 20/6/2016

Aceptado: 19/9/2016

Para citar este artículo / To cite this article:

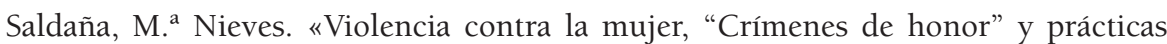
culturales y religiosas perjudiciales: estándares internacionales de derechos humanos adoptados por las Naciones Unidas». En Nieves Montesinos Sánchez y Beatriz Souto Galván (coords.), Laicidad y creencias. Feminismo/s, 28 (diciembre 2016): 91-132, DOI: 10.14198/fem.2016.28.04

Para enlazar con este artículo / To link to this article:

http://dx.doi.org/10.14198/fem.2016.28.04

\section{Resumen}

A lo largo de los últimos veinte años, las Naciones Unidas han abordado los llamados «crímenes de honor» como una forma específica de violencia contra la mujer, basada en prácticas perjudiciales que son consecuencia de tradiciones culturales y religiosas arraigadas, que discriminan a las mujeres y las niñas y violan sus derechos humanos 
y fundamentales, de ahí que las Naciones Unidas hayan definido un conjunto de estándares internacionales de derechos humanos que deben guiar la actuación de los Estados para prevenir, combatir y erradicar los «crímenes de honor».

Palabras clave: Naciones Unidas, derechos humanos, violencia contra la mujer, prácticas culturales y religiosas perjudiciales, «crímenes de honor».

\begin{abstract}
Over the last twenty years, the United Nations have addressed so-called «honor crimes» as a specific form of violence against woman, based on harmful practices that are the result of cultural and religious traditions rooted, that discriminate against women and girls and violate their fundamental and human rights, so that the United Nations has defined a set of international human rights standards that must guide the actions of States to prevent, combat and eradicate «honor crimes».
\end{abstract}

Keywords: United Nations, human rights, violence against woman, harmful cultural and religious practices, «honor crimes». 


\section{VIOLENCIA CONTRA LA MUJER Y «CRÍMENES DE HONOR»: CULTURA, LIBERTAD DE RELIGIÓN Y CREENCIAS Y UNIVERSALIDAD DE LOS DERECHOS HUMANOS}

\subsection{Violencia contra la mujer y «crímenes de honor»}

La Declaración Universal de Derechos Humanos de (DUDH) de 1948 establece que toda persona tiene todos los derechos y libertades proclamados en la Declaración sin distinción alguna, entre otras causas, por razón de sexo (art. 2), y reconoce el derecho a la vida, a la libertad y a la seguridad de la persona (art. 3). De igual manera, el Pacto Internacional de Derechos Civiles y Políticos (PIDCP) de 1966 establece que cada uno de los Estados parte se compromete a respetar y a garantizar a todas las personas que se encuentren en su territorio y estén sujetas a su jurisdicción los derechos reconocidos en el Pacto sin distinción alguna, entre otros motivos, por razón de sexo (art. 2.1.) y a garantizar a hombres y mujeres la igualdad en el goce de todos los derechos civiles y políticos enunciados en el Pacto (art. 3), reconociéndose que todos los seres humanos tienen el derecho inherente a la vida, sin que nadie pueda ser privado de ella arbitrariamente (art. 6.1).

Igualmente, la Convención sobre la Eliminación de todas las Formas de Discriminación contra la Mujer (CEDAW por sus siglas en inglés) de 1979 obliga a los Estados parte a eliminar sin dilación todo tipo de discriminación contra la mujer, incluidas las practicadas por cualesquiera personas, organizaciones o empresas, garantizando, a través de los tribunales y las instituciones públicas, la protección efectiva de la mujer contra todo acto de discriminación, castigando a los autores de tales actos, derogando todas las disposiciones penales nacionales que constituyan discriminación contra la mujer (art. 2), modificando los patrones socioculturales de conducta de hombres y mujeres y eliminando los prejuicios y las prácticas consuetudinarias y de cualquier otra índole que estén basados en la idea de la inferioridad o superioridad de cualquiera de los sexos o en funciones estereotipadas de hombres y mujeres (art. 5).

Asimismo, la Declaración sobre la eliminación de la violencia contra la mujer (DEVAW por sus siglas en inglés) de 1993, afirma que la violencia contra la mujer, en todas sus formas y manifestaciones, constituye una violación de sus 
derechos humanos y libertades fundamentales que impide total o parcialmente a la mujer ejercitar dichos derechos y libertades, instándose a los Estados a condenar la violencia contra la mujer y a no invocar ninguna costumbre, tradición o consideración religiosa para eludir su obligación de procurar eliminarla (art. 4). Y la Plataforma de Acción de Beijing de 1995 insta a los Estados a adoptar medidas integrales para prevenir y eliminar la violencia contra la mujer, especialmente, a condenar la violencia contra la mujer y abstenerse de invocar ninguna costumbre, tradición o consideración de carácter religiosa o cultural para eludir las obligaciones con respecto a su eliminación que figuran en la Declaración sobre la Eliminación de la Violencia contra la Mujer ${ }^{1}$.

Sin embargo, a pesar de este marco normativo, las mujeres sigue siendo víctimas de distintos tipos de violencia en los países de todo el mundo, destacando especialmente los llamados «crímenes de honor» (Terman 1), una forma específica de violencia contra la mujer derivada de prácticas culturales y religiosas basadas en el supuesto «honor» de la familia, que se comente, por lo común por un hermano, el padre, el marido u otro pariente masculino, contra mujeres e incluso niñas porque los familiares consideran que un determinado comportamiento supuesto, subjetivo o real traerá la deshonra a la familia o la comunidad, incluyéndose, entre otros comportamientos, mantener relaciones sexuales antes de contraer matrimonio, negarse a aceptar un matrimonio arreglado, contraer matrimonio sin el consentimiento de los padres, cometer adulterio, pedir el divorcio, vestir de una manera que la comunidad considere inaceptable, trabajar fuera de casa o, en general, no ajustarse a los papeles estereotipados asignados a cada género, e incluso por haber sido víctima de violencia sexual. Aunque existen diversos tipos de "crímenes de honor», como la mutilación de miembros, la flagelación y la violencia con ácido, las manifestaciones más severas son los asesinatos en nombre del «honor», en los que las víctimas son enterradas vivas, quemadas, apuñaladas, estranguladas y apedreadas hasta la muerte (lapidación) (Kusha y Ammar 1-2), incluso, se obliga a las mujeres a suicidarse tras denunciar públicamente su comportamiento, como es el caso de la autoinmolación, consistente en que las mujeres o las jóvenes tratan de suicidarse prendiéndose fuego porque consideran que están «deshonrando» a la familia².

1. ONU, Informe de la IV Conferencia Mundial sobre la Mujer, Beijing, 4 a 15 de septiembre de 1995, New York, 1995, párr. 124. a) (UN Doc. A/CONF.177/20/Rev.1).

2. Entre otros países, especialmente se han detectado casos en Afganistán e Irán, ver ONU, Asamblea General, Consejo de Derechos Humanos, Informe de la Relatora Especial sobre la violencia contra la mujer, sus causas y sus consecuencias, la Sra. Rashida Manjoo, 23 de mayo de 2012, párr. 48 (UN Doc. A/HRC/20/16). 
Realmente, lo que se esconde bajo este tipo de crímenes es la necesidad de controlar la sexualidad de las mujeres y su libertad, haciéndose recaer el supuesto «honor» de la familia sobre ellas, por lo que son sometidas a un estricto control no solo de su conducta sexual sino de todo su comportamiento, de manera que las mujeres que se consideran transgresoras de los límites del comportamiento apropiado son víctimas de este tipo de crímenes, que normalmente son llevados a cabo por los varones de la familia, a veces menores de edad, para reducir la pena, teniendo estos tipos de crímenes una dimensión colectiva, pues la familia o incluso la comunidad en su conjunto se considera lesionada por el comportamiento real o percibido de la mujer, y un carácter público, influyendo en la conducta de otras mujeres ${ }^{3}$.

La violencia contra las mujeres basada en el «honor» se produce en muy diversos países, entre otros, Bangladesh, Egipto, India, Irán, Israel, Jordania, Líbano, Marruecos, Pakistán, Siria, Turquía, Yemen, aunque también ha tenido lugar en las comunidades inmigrantes de países europeos como Alemania, Francia, Reino Unido y Suecia ${ }^{4}$. Aunque no existen estadísticas precisas sobre el número de mujeres asesinadas por sus familiares, según el Fondo de Población Mundial de las Naciones Unidas (UNFPA por sus siglas en inglés), se estima que al menos 5.000 mujeres son asesinadas al año por miembros de sus propias familias víctimas de la violencia por razones de «honor», aunque es muy probable que las cifras sean muy superiores, pues en muchos casos estos crímenes se ocultan bajo la forma de accidentes o suicidios (United Nations Population Fund 29).

A pesar de constituir una flagrante vulneración de los derechos humanos de las mujeres, en diversos países los crímenes por razones de «honor» muchas veces no se denuncian ni se investigan, por lo que suelen quedar impunes, y cuando son sancionados las sentencias son mucho más leves que las que se imponen por crímenes igualmente violentos sin la dimensión del «honor», al no estar suficientemente castigados por la legislación penal, contemplándose reducciones, eximentes y exoneraciones de las penas impuestas ${ }^{5}$. Con frecuen-

3. Ver ONU, Asamblea General, Informe del Secretario General relativo a «Estudio a fondo sobre todas las formas de violencia contra la mujer», Sexagésimo primer período de sesiones de la Asamblea General, 6 de julio de 2006, párr. 84 (UN Doc. A/61/122/Add.1).

4. Ver ONU, Consejo Económico y Social, Comisión de Derechos Humanos, Informe de la Relatora Especial sobre la violencia contra la mujer, sus causas y consecuencias, Sra. Radhika Coomaraswamy, presentado de conformidad con la Resolución 2001/49 de la Comisión de Derechos Humanos, sobre «Prácticas culturales dentro de la familia que entrañan violencia contra la mujer», de 31 de enero de 2002, especialmente párr. 21-37 (UN Doc. E/CN.4/2002/83).

5. Ver ONU, Asamblea General, Consejo de Derechos Humanos, Informe de la Relatora Especial sobre la violencia contra la mujer, sus causas y sus consecuencias, la Sra. Rashida Manjoo, 23 de mayo de 2012, párrs. 43-50 (UN Doc. A/HRC/20/16). 
cia se aprueban y toleran los crímenes cometidos por motivos de «honor» como un medio para preservar o restablecer la integridad de prácticas y tradiciones culturales o religiosas discriminatorias que regulan la posición subordinada de la mujer en la familia, la comunidad y la sociedad. Por tanto, esta cuestión afecta al alcance del concepto de la universalidad de los derechos humanos en relación con el respeto y la protección de las normas culturales y religiosas, incluso aunque contravengan los derechos humanos de las mujeres (Nyamu 381; Raday 2003, 663; Wyttenbach 225).

\subsection{Cultura, libertad de religión y creencias y prácticas tradicionales perjudiciales contra la mujer}

Sin duda, la cultura está presente en todas las manifestaciones humanas, incluidos los ordenamientos jurídicos, y en todas las sociedades pasadas, presentes y futuras, generándose y transformándose de manera interactiva, progresiva, cambiante y dinámica. Sin embargo, muchas prácticas y normas que discriminan a las mujeres se justifican en base a la cultura, de manera que puede afirmarse que nadie ha padecido mayores violaciones de sus derechos humanos en nombre de la cultura que las mujeres, resultando preocupante la utilización de argumentos del relativismo cultural para poner en duda la legitimidad y la aplicabilidad universal de las normas de derechos humanos de las mujeres, que se ven amenazados, e incluso totalmente sacrificados, por afirmaciones de prácticas y reivindicaciones culturales específicas en muchas partes del mundo, predominando la violencia contra la mujer cometida en nombre o con el pretexto de la cultura, la costumbre, la tradición o la religión, aceptándose que los sistemas judiciales reduzcan o incluso no sancionen los actos de violencia contra la mujer, o que impongan graves formas de castigo a las mujeres que supuestamente transgreden las normas sociales ${ }^{6}$.

6. Ver ONU, Asamblea General, Informe de la Relatora Especial sobre los derechos culturales, Farida Shaheed, de conformidad con lo dispuesto en la Resolución 19/6 del Consejo de Derechos Humanos, 10 de agosto de 2012, párr. 3 (UN Doc. A/67/287). La Relatora Especial sobre la violencia contra la mujer ha propuesto diversas directrices para abordar la cuestión de la cultura y la violencia contra la mujer, entre otras: a) Cuestionar la cultura como algo construido históricamente y que representa diversas posiciones e intereses subjetivos; b) Aplicar una perspectiva política y económica a la comprensión de las prácticas culturales, abordando los factores sociales, económicos y políticos que sustentan y refuerzan los paradigmas culturales nocivos que subordinan a las mujeres, ver ONU, Asamblea General, Consejo de Derechos Humanos, Informe de la Relatora Especial sobre la violencia contra la mujer, sus causas y consecuencias, Yakin Ertürk, relativo a las «Intersecciones entre la cultura y la violencia contra la mujer», 17 de enero de 2007, párrs. 67 y ss. (UN Doc. A/HRC/4/34). 
Aunque diversos instrumentos internacionales reconocen el derecho de todo ser humano a vivir conforme a sus tradiciones culturales, sin embargo, estos derechos se reconocen bajo la condición de que en su ejercicio los derechos humanos de los demás, incluidas las mujeres, no sean de ninguna forma restringidos o vulnerados (Koukoulis-Spiliotopoulos, 418). Así, la Convención sobre la Protección y Promoción de la diversidad de las expresiones culturales, adoptada por la Conferencia General de la Organización de las Naciones Unidas para la Educación, la Ciencia y la Cultura (UNESCO) en París el 20 de octubre de 2005, establece que «nadie podrá invocar las disposiciones establecidas en la propia Convención para atentar contra los derechos humanos y las libertades fundamentales proclamados en la Declaración Universal de Derechos Humanos y garantizados por el Derecho internacional, o para limitar su ámbito de aplicación» (art. 2). Sin embargo, diversas prácticas culturales perjudiciales para la mujer son reivindicadas por personas o comunidades, o incluso por Estados, que ejercen esas prácticas o las perciben como un elemento de la libertad de religión que tiene sus raíces en convicciones profundas y en prescripciones, mandamientos o valores fundados en la religión o atribuidos a ésta ${ }^{7}$.

En efecto, la mayoría de las prácticas tradicionales perjudiciales contra la mujer tienen su fundamento en tradiciones o costumbres religiosas y culturales fundadas e una interpretación cultural y ancestral de la religión y de los preceptos religiosos errónea que justifica la pervivencia de mecanismos de control y discriminación hacia la mujer, denegándole los derechos más elementales. Realmente, en las sociedad patriarcales, la posición de preferencia y predominio de los varones ha favorecido una interpretación equivocada y un alcance de las religiones discriminatorio para las mujeres lo que ha originado y justificado prácticas perjudiciales que vulneran sus derechos y libertades fundamentales ${ }^{8}$.

7. Como expone el Relator Especial de la Comisión de Derechos Humanos sobre la libertad de religión o de creencias, la cultura patriarcal dominante en la que germinan y se asientan las distintas religiones constituye un factor determinante para la milenaria situación de discriminación hacia la mujer y la justificación y persistencia de costumbres y tradiciones religiosas perjudiciales, ver ONU, Consejo Económico y Social, Comisión de Derechos Humanos, Informe presentado por el Sr. Abdelfattah Amor, Relator Especial sobre la libertad de religión o de creencias, de conformidad con la Resolución 2001/42 de la Comisión de Derechos Humanos, relativo a «Estudio sobre la libertad de religión o de creencias y la condición de la mujer en relación con la religión y las tradiciones», 5 de abril de 2002, párrs. 13, 15 y 17 (UN Doc. E/CN.4/2002/73/Add.2).

8. Como señala el Relator Especial sobre la libertad de religión o de creencias, la preferencia por los varones es un valor muy difundido en todos los continentes, lo que se explica por la existencia de modelos patriarcales y de una interpretación discriminatoria de la religión, ver ONU, Consejo Económico y Social, Comisión de Derechos Humanos, Informe presentado por el Sr. Abdelfattah Amor, Relator Especial sobre la libertad de religión o de creencias, de conformidad con la Resolución 2001/42 de la Comisión de Derechos

Feminismo/s 28, diciembre 2016, pp. 91-132 
La manifestación más extrema de la vulneración de los derechos de las mujer fundada en una interpretación discriminatoria de la religión se manifiesta en los supuestos de integrismos y extremismos religiosos, que niegan, incluso por medios violentos, la igualdad entre hombres y mujeres, y que incluso pueden alcanzar amparo en el propio Estado, institucionalizándose la discriminación contra la mujer ${ }^{9}$. En consecuencia, en las Constituciones que proclaman la religión del Estado, o en las sociedades en las que la religión ocupa un lugar hegemónico en la vida de los individuos y de los grupos, está en juego el respeto de los derechos humanos de la mujer. Incluso, se puede apreciar la perpetuación de la discriminación de la mujer a pesar de los avances en la laicización de la sociedad y el Estado, como señala el Relator Especial de la Comisión de Derechos Humanos sobre la libertad de religión o de creencias, «a veces resulta difícil distinguir lo cultural de lo religioso y decir que una práctica, una norma o una representación negativa de la mujer en la familia y la sociedad tienen un fundamento únicamente cultural, sociocultural o consuetudinario. En muchas sociedades, incluidas las industrializadas, la imagen de la mujer en la cultura dominante no se libra de cierto fondo, también religioso, que tal vez no se manifieste como tal, pero que se transmite y se halla difuso en la conciencia colectiva ancestral de la sociedad y no ha desaparecido totalmente con el desarrollo o con los movimientos de laicización de la sociedad y del Estado» ${ }^{10}$.

Humanos, relativo a «Estudio sobre la libertad de religión o de creencias y la condición de la mujer en relación con la religión y las tradiciones», 5 de abril de 2002, párr. 94 (UN Doc. E/CN.4/2002/73/Add.2).

9. Ver ONU, Asamblea General, Informe provisional sobre la eliminación de todas las formas de intolerancia y discriminación fundadas en la religión o las convicciones, preparado por el Sr. Abdelfattah Amor, Relator Especial de la Comisión de Derechos Humanos, de conformidad con la Resolución 54/159 de la Asamblea General, de 17 de diciembre de 1999, 8 de septiembre de 2000, párrs. 77 y ss. (UN Doc. A/55/280). Así en el caso extremo de Afganistán, la discriminación contra la mujer fue institucionalizada por los talibanes con su propia interpretación del Islam, siendo excluidas de la sociedad, el empleo, la escuela, obligadas a llevar el burka en público, etc., ver ONU, Consejo Económico y Social, Comisión de Derechos Humanos, Informe presentado por el Sr. Abdelfattah Amor, Relator Especial, de conformidad con la Resolución 1998/18 de la Comisión de Derechos Humanos, relativo a «Los derechos civiles y políticos, en particular las cuestiones relacionadas con la intolerancia religiosa», 11 de enero de 1999, párr. 26 (UN Doc. E/CN.4/1999/58).

10. ONU, Consejo Económico y Social, Comisión de Derechos Humanos, Informe presentado por el Sr. Abdelfattah Amor, Relator Especial sobre la libertad de religión o de creencias, de conformidad con la Resolución 2001/42 de la Comisión de Derechos Humanos, relativo a «Estudio sobre la libertad de religión o de creencias y la condición de la mujer en relación con la religión y las tradiciones», 5 de abril de 2002, párr. 24 (UN Doc. E/CN.4/2002/73/Add.2). 
Se plantea, por tanto, en estos casos un conflicto entre el respeto de los derechos humanos de las mujeres y las especificidades culturales que tienen su fundamento en la libertad de religión y creencias, reconocida expresamente como libertad individual y colectiva. En efecto, el Pacto Internacional de Derechos Civiles y Politicos reconoce en el art. 18 el derecho a la libertad de pensamiento, de conciencia y religión, incluyéndose el derecho a mantener cualquier clase de creencias religiosas o ninguna, así como la libertad de manifestar la religión o creencias individual o colectivamente, tanto en público como en privado, afirmándose expresamente que nadie será objeto de medidas coercitivas que puedan menoscabarla. Sin embargo, esta libertad no está exenta de limitaciones, estableciéndose expresamente que la libertad de manifestar la propia religión o las propias creencias está sujeta a las limitaciones prescritas por la ley que sean necesarias para proteger la seguridad, el orden, la salud o la moral públicos, o los derechos y libertades fundamentales de los demás, incluyéndose el derecho a la igualdad de género, que protege el art. 3 del propio Pacto (Raday 2007, 75).

Por lo tanto, la libertad de religión y creencias no puede invocarse para justificar la violación de los derechos humanos y las libertades de las mujeres y niñas. Así, la Declaración sobre la eliminación de todas las formas de intolerancia y discriminación fundada en la religión o las convicciones, adoptada por Resolución 36/55 de la Asamblea General el 25 de noviembre de 1981, define esas formas de intolerancia y discriminación como «toda distinción, exclusión, restricción o preferencia fundada en la religión o en las convicciones y cuyo fin o efecto sea la abolición o el menoscabo del reconocimiento, el goce o el ejercicio en pie de igualdad de los derechos humanos y las libertades fundamentales» (art. 2), señalando expresamente que no se puede perjudicar la salud física o mental de un niño o niña por la práctica de la religión o las convicciones (art. 5.5).

Igualmente, en la Observación General No. 28 del Comité de Derechos Humanos, de 29 de marzo de 2000, sobre «La igualdad de derechos entre hombres y mujeres (Artículo 3)», en la que se analizan los importantes efectos que tiene el artículo 3 del PIDCP en el efectivo ejercicio por las mujeres de los derechos humanos amparados por el Pacto, el Comité señala expresamente que la desigualdad que padecen las mujeres en el mundo en el disfrute de sus derechos está profundamente arraigada en la tradición, la historia, la cultura, incluso en las actitudes religiosas, debiendo cerciorarse los Estados de que no se utilicen actitudes tradicionales, históricas, religiosas o culturales como pretexto para justificar la vulneración del derecho de la mujer a la igualdad ante la ley $\mathrm{y}$ al disfrute en condiciones de igualdad de todos los derechos previstos en el 
Pacto, no pudiéndose invocar el art. 18 para justificar la discriminación contra la mujer aduciendo la libertad de pensamiento, de conciencia y de religión ${ }^{11}$.

Asimismo, aunque en ninguna de las disposiciones de la Convención sobre la Eliminación de todas las Formas de Discriminación contra la Mujer se utilizan los términos de religión o tradiciones religiosas, sin embargo, deben considerarse incluidas en el artículo 5 cuando establece expresamente que los Estados tomarán medidas para modificar los patrones socioculturales de conducta de hombres y mujeres, eliminando los prejuicios y las prácticas consuetudinarias y de cualquier otra índole que estén basados en la idea de la inferioridad o superioridad de cualquiera de los sexos o en funciones estereotipadas de hombres y mujeres, incluyéndose, por lo tanto las discriminaciones de origen religioso (Holtmaat y Naber, 29). Por esto no extraña, que, como se analiza con detenimiento más adelante, muchas de las reservas a la Convención presentadas por los Estados, especialmente a los arts. 5 y 16, se refieren a disposiciones particulares de la Convención consideradas por el Estado incompatibles con una legislación interna de inspiración religiosa o con un artículo de la Constitución que hace referencia a la religión, fundamentándose en motivos religiosos relacionados con el estatuto jurídico discriminatorio que se atribuye en sus ordenamiento a las mujeres ${ }^{12}$. Sin duda estas reservas de los Estados basadas en motivos de carácter religioso son contrarias al propósito y finalidad de la Convención, pues contribuyen a perpetuar las discriminaciones que afectan a las mujeres en esos países fundada en costumbres y tradiciones religiosas ${ }^{13}$.

Realmente, estas reservas a la Convención reflejan el problema planteado de la compatibilidad de la religión y las creencias con los derechos humanos de la mujer, sin embargo, no puede aceptarse la idea de que la libertad de religión o de creencias y la igualdad entre hombres y mujeres constituyan normas de derechos humanos contradictorias, que se oponen entre sí de forma absoluta, pues en última instancia asumir esta presunción puede conducir a aceptar planteamientos del relativismo cultural y a cuestionar la universalidad

11. ONU, Comité de Derechos Humanos, Observación General núm. 28 sobre «La igualdad de derechos entre hombres y mujeres (Artículo 3)», 29 de marzo de 2000, especialmente párrs. 5, 9 y 21 (UN Doc. CCPR/C/21/Rev.1/Add.10).

12. ONU, CEDAW, Comité para la Eliminación de la Discriminación contra la Mujer, Reservas a la Convención sobre la Eliminación de todas las Formas de Discriminación contra la Mujer, Informe de la Secretaría, 12 de noviembre de 1996, párrs. 5, 6, 12 (UN Doc. CEDAW/C/1997/4).

13. Las reservas presentadas por los Estados a la Convención pueden consultarse en United Nations Entity for Gender Equality and the Empowerment of Women, Convention on the Elimination of All Forms of Driscrimination against Women, Reservations to CEDAW, <http://www.un.org/womenwatch/daw/cedaw/reservations.htm>, consultado 22-05-2016. 
de los derechos humanos de las mujeres, que son la mitad del género humano, cuando entran en conflicto con prácticas tradicionales religiosas y culturales perjudiciales (Zechenter, 341).

\subsection{La universalidad de los derechos humanos de las mujeres y las niñas}

La universalidad es inherente a los derechos humanos, pues tal como se proclamó en la Conferencia Mundial de Derechos Humanos celebrada en Viena en 1993, todos los derechos humanos son universales, indivisibles e interdependientes y están relacionados entre sí, debiendo tratarse los derechos humanos en forma global y de manera justa y equitativa, en pie de igualdad y dándoles a todos el mismo peso, de ahí que, aún teniendo en cuenta la importancia de las particularidades nacionales y regionales, así como de los diversos patrimonios históricos, culturales y religiosos, los Estados deban, sean cuales fueren sus sistemas políticos, económicos y culturales, promover y proteger todos los derechos humanos y las libertades fundamentales». Por consiguiente, como se reconoce también en la Declaración y Programa de Acción de Viena, «Los derechos humanos de la mujer y de la niña son parte inalienable, integrante e indivisible de los derechos humanos universales. La plena participación, en condiciones de igualdad, de la mujer en la vida política, civil, económica, social y cultural en los planos nacional, regional e internacional y la erradicación de todas las formas de discriminación basadas en el sexo son objetivos prioritarios de la comunidad internacional», instándose a todos los Estados a que adopten las medidas apropiadas para hacer frente a la intolerancia y a otras formas análogas de violencia fundadas en la religión o las convicciones, especialmente las prácticas de discriminación contra la mujer, a eliminar la violencia contra la mujer en la vida pública y privada, y a erradicar los conflictos que puedan surgir entre los derechos de la mujer y las consecuencias perjudiciales de ciertas prácticas tradicionales o costumbres, de prejuicios culturales y del extremismo religioso ${ }^{14}$.

Por lo tanto, la universalidad de los derechos humanos permite afirmar la preeminencia, por encima de toda costumbre o tradición de carácter religioso o cultural, del respeto a la dignidad de la mujer y a sus derechos humanos inalienables, sin excluir las especificidades culturales, siempre que integren los elementos de la universalidad y no nieguen la dignidad de la mujer ${ }^{15}$. En este

14. ONU, Asamblea General, Declaración y Programa de Acción de Viena, Conferencia Mundial de Derechos Humanos, Viena, 14 a 25 de junio de 1993, Part. I, Cap. III, párrs. 5, 18, 22 y 38 (UN Doc. A/CONF.157/24 (Part I).

15. Como expone el Relator Especial de la Comisión de Derechos Humanos sobre la libertad de religión o de creencias la universalidad de los derechos humanos es hoy en día

Feminismo/s 28, diciembre 2016, pp. 91-132 
sentido, resulta sorprendente que todavía no se haya adoptado por las Naciones Unidas un documento específico sobre los derechos de la mujer en relación con las tradiciones religiosas y culturales que coadyuve a reafirmar los derechos humanos de las mujeres como derechos humanos universales que deben ser respetados y garantizados por todos los Estados, sin que puedan quedar subordinados a prácticas y tradiciones religiosas y culturales perjudiciales ${ }^{16}$.

Por todo, la cultura y la religión no pueden justificar la discriminación y vulneración de los derechos humanos de las mujeres. Los principios de igualdad, no discriminación y respeto a la dignidad de la mujer y a la universalidad de los derechos humanos deben prevalecer sobre las tradiciones religiosas o culturales y el deseo de los Estados de preservarlas (An-Na 'im, 167). La universalidad de los derechos humanos puede conjugarse con el respeto de las tradiciones religiosas siempre que éstas no vulneren la integridad y dignidad de la mujer como ser humano, en caso contrario, se podría justificar cualquier práctica fundada en una determinada interpretación religiosa aunque atentara contra la integridad o la propia vida de la mujer, como es el caso de los llamados crímenes en nombre del «honor» ${ }^{17}$. De ahí que, como se analiza a continuación, a lo largo

una noción perfectamente admitida, un derecho adquirido que ya no tiene vuelta atrás, inherente a la naturaleza del ser humano, y dimana de que los derechos de la mujer, aun cuando atañen a aspectos culturales y religiosos, forman parte de los derechos fundamentales del ser humano, y procede de «la dignidad, consustancial e inherente a la persona humana»; de manera que cuando se ataca a la mujer en su dignidad, ya no hay lugar ni para la soberanía ni para las especificidades culturales o religiosas, ONU, Consejo Económico y Social, Comisión de Derechos Humanos, Informe presentado por el Sr. Abdelfattah Amor, Relator Especial sobre la libertad de religión o de creencias, de conformidad con la Resolución 2001/42 de la Comisión de Derechos Humanos, relativo al «Estudio sobre la libertad de religión o de creencias y la condición de la mujer en relación con la religión y las tradiciones», 5 de abril de 2002, párr. 29 (UN Doc. E/ CN.4/2002/73/Add.2).

16. Realmente, el Relator Especial sobre libertad de religión o de creencias propuso en 2002 la adopción de una Declaración sobre la situación de la mujer en relación con la religión para reafirmar los derechos de las mujer, ver ONU, Consejo Económico y Social, Comisión de Derechos Humanos, Informe presentado por el Sr. Abdelfattah Amor, Relator Especial sobre la libertad de religión o de creencias, de conformidad con la Resolución 2001/42 de la Comisión de Derechos Humanos, relativo al «Estudio sobre la libertad de religión o de creencias y la condición de la mujer en relación con la religión y las tradiciones», 5 de abril de 2002, párr. 225 (UN Doc. E/CN.4/2002/73/ Add.2). Sin embargo, transcurridos ya 14 años las Naciones Unidas no han adoptado todavía un documento al respecto.

17. Como señala el Relator Especial de la Comisión de Derechos Humanos sobre la libertad de religión o de creencias, el relativismo cultural no es incompatible con la universalidad de los derechos de la mujer, sino sólo en la medida en que vulnera la integridad y la dignidad de la mujer como ser humano, si se admitiera lo contrario todas las prácticas culturales o religiosas serían defendibles en nombre precisamente de la libertad de

Feminismo/s 28, diciembre 2016, pp. 91-132 
de los últimos 20 años las Naciones Unidas hayan abordado de forma especial los «crímenes de honor» como una manifestación grave de la violencia contra la mujer basada en prácticas tradicionales perjudiciales ${ }^{18}$ que son consecuencia de tradiciones culturales y religiosas arraigadas que discriminan a la mujer y violan sus derechos humanos y fundamentales (Winter, Thompson, Jeffreys 72-73), adoptándose incluso por la Asamblea General tres Resoluciones específicas ${ }^{19}$, configurándose así un conjunto de estándares normativos y jurídicos internacionales de derechos humanos para la prevención y erradicación de los «crímenes de honor», que requiere la adopción por los Estados de una estrategia integral dirigida al reforzamiento de medidas jurídicas, políticas y de carácter social.

\section{PRÁCTICAS CULTURALES Y RELIGIOSAS PERJUDICIALES, VIOLENCIA CONTRA LA MUJER Y «CRÍMENES DE HONOR»}

Los «crímenes de honor» justificados, en una gran parte de los casos, en el respeto a determinadas tradicionales religiosas y culturales constituyen manifestaciones específicas de la violencia ejercida contra la mujer y por tanto una vulneración de sus derechos humanos y libertades fundamentales reconocidos en la Declaración Universal de Derechos Humanos y el Pacto Internacional de Derechos Civiles y Políticos, especialmente, del derecho a la vida, a la libertad y la seguridad de la persona; a no estar sujeta a torturas ni a tratos o penas crueles, inhumanos o degradantes; a la igual protección de las leyes; al más alto nivel posible de salud física y mental y al derecho a la igualdad y a la prohibición de discriminación por razón de sexo, de ahí que en los últimos años las Naciones Unidas hayan adoptado distintos instrumentos, resoluciones y mecanismos que fomentan la implementación de políticas y estrategias integrales por los Estados para su erradicación ${ }^{20}$.

religión, incluso cuando atentan contra la salud o la vida de la mujer, ONU, Consejo Económico y Social, Comisión de Derechos Humanos, Informe presentado por el Sr. Abdelfattah Amor, Relator Especial sobre la libertad de religión o de creencias, de conformidad con la Resolución 2001/42 de la Comisión de Derechos Humanos, relativo al «Estudio sobre la libertad de religión o de creencias y la condición de la mujer en relación con la religión y las tradiciones», 5 de abril de 2002, párr. 64 (E/CN.4/2002/73/Add.2).

18. Ver ONU, United Nations Division for the Advancement of Women, The CEDAW Convention and Harmful Practices Against Women: The Work of the CEDAW Committee, 11 May 2009 (EGM/GPLVAW/2009/EP.05).

19. Resoluciones A/RES/59/165, de 20 de diciembre de 2004; A/RES/57/179, de 18 de diciembre de 2002; y A/RES/55/66, de 4 de diciembre de 2000. El Secretario General ha abordado los «crímenes de honor» contra las mujeres en un informe específico, ver Informe A/57/169, de 2 de julio de 2002.

20. El artículo 3 de la Declaración Universal de Derechos Humanos (DUDH), adoptada por la Asamblea General de las Naciones Unidas el 10 de diciembre de 1948 [G.A. RES. 217A

Feminismo/s 28, diciembre 2016, pp. 91-132 
2.1 La incompatibilidad de las reservas de los Estados a la Convención sobre la Eliminación de todas las formas de Discriminación contra la Mujer (CEDAW) en base a legislación nacional de carácter religioso, tradicional o cultural

La Convención sobre la Eliminación de todas las formas de Discriminación contra la Mujer (CEDAW por sus siglas en ingles), adoptada por Resolución 34/180, de la Asamblea General, de 18 de diciembre de 1979, que establece un marco global de acción a nivel nacional e internacional para la erradicación de la discriminación contra la mujer tanto en sus manifestaciones generales como específicas (Freeman, Rudolf, Chinkin), exige a los Estados que: consagren en sus Constituciones nacionales o en la legislación apropiada el principio de la igualdad del hombre y la mujer, asegurándose por ley su realización práctica (art. 2.a); adopten medidas legislativas y de otro carácter que prohíban toda discriminación contra la mujer (art. 2.b); ofrezcan igual protección de la ley para los derechos de mujeres y hombres y que garanticen, a través de los tribunales nacionales competentes, la protección efectiva de las mujeres frente a la discriminación (art. 2.c); tomen las medidas apropiadas para eliminar la discriminación contra la mujer practicada por cualesquiera personas, organizaciones o empresas (art. 2.e); adopten todas las medidas adecuadas, incluso de carácter legislativo, para modificar o derogar leyes, reglamentos, usos y prácticas que constituyan discriminación contra la mujer (art. 2.f); deroguen todas las disposiciones penales nacionales que constituyan discriminación contra la mujer (art. 2.g); tomen todas las medidas apropiadas para modificar los patrones socioculturales de conducta de hombres y mujeres, con miras a alcanzar la eliminación de los prejuicios y las prácticas consuetudinarias y de cualquier otra índole que estén basados en la idea de la inferioridad o superioridad de cualquiera de los sexos o en funciones estereotipadas de hombres

(III)], establece que «Toda persona tiene derecho a la vida, a la libertad y a la seguridad de su persona». Este derecho fue reafirmado en el Pacto Internacional de Derechos Civiles y Políticos (PIDCP), adoptado por la Asamblea General el 16 de diciembre de 1966 (A/ RES. 2200A (XXI), que protege el derecho a la vida (art. 6) y el derecho a la libertad y a la seguridad de la persona (ar. 9). Asimismo, el derecho a no ser sometido a torturas ni a penas o tratos crueles, inhumanos o degradantes es reconocido en el art. 5 de la DUDH y en el art. 7 del PIDCP. Estos derechos, así como otros reconocidos en la DUDH, el PIDCP y el Pacto Internacional de Derechos Económicos, Sociales y Culturales (PIDESC), adoptado por la Asamblea General el 16 de diciembre de 1966 (A/RES. 2200A (XXI), tales como el derecho a la igual protección ante la ley (art. 14 PIDCP) y el derecho al más alto nivel posible de salud física y mental (art. 12 (PIDESC), están implicados en casos de violencia contra la mujer, de ahí que los Estados que son parte en estos instrumentos tienen obligación de proteger a las mujeres contra toda forma de violencia. 
y mujeres (art. 5.a) (Raday 2007, 73-77); y que adopten todas las medidas adecuadas para eliminar la discriminación contra la mujer en todos los asuntos relacionados con el matrimonio y las relaciones familiares (art. 16).

Aunque la Convención no se refiere expresamente a la violencia de género, sin embargo, en el Preámbulo de la Recomendación General N. ${ }^{\circ} 12$ (1989) del Comité para la Eliminación de la Discriminación contra la Mujer sobre «Violencia contra la mujer», se afirma expresamente que los artículos 2, 5 y 16 de la Convención obligan a los Estados parte a proteger a la mujer contra cualquier tipo de violencia que se produzca en la familia, en el trabajo o en cualquier otro ámbito de la vida social y se recomienda a los Estados que incluyan en sus informes periódicos al Comité información sobre la legislación vigente para proteger a las mujeres de la frecuencia de cualquier tipo de violencia en la vida cotidiana (violencia sexual, malos tratos en el ámbito familiar, acoso sexual en el lugar de trabajo, etc.), los servicios de apoyo a las mujeres que sufren agresiones o malos tratos, así como los datos estadísticos sobre la frecuencia de cualquier tipo de violencia contra la mujer y sobre las mujeres víctimas de la violencia ${ }^{21}$.

Asimismo, en la Recomendación General N. ${ }^{\circ} 19$ (1992) del Comité para la Eliminación de la Discriminación contra la Mujer sobre «La violencia contra la mujer» se establece que la violencia contra la mujer, que menoscaba o anula el goce de sus derechos humanos y libertades fundamentales en virtud del Derecho internacional o de los diversos convenios de derechos humanos, constituye una forma de discriminación contra la mujer, incluyéndose los actos que infligen daños o sufrimientos de índole física, mental o sexual, las amenazas de cometer esos actos, la coacción y otras formas de privación de la libertad, afirmándose expresamente que las actitudes tradicionales que consideran a la mujer como subordinada o le atribuyen funciones estereotipadas perpetúan la difusión de prácticas que entrañan violencia o coacción, como la violencia y los malos tratos en la familia, los matrimonios forzados, el asesinato por presentar dotes insuficientes, los ataques con ácido y la mutilación genital, prejuicios y prácticas que pueden llegar a justificar la violencia contra la mujer como una forma de protección o dominación, recomendándose a los Estados a que actúen con la «diligencia debida» para combatir los actos públicos o privados de violencia contra las mujeres, y, especialmente, en relación con los «crímenes de honor», que eliminen de la legislación la defensa del «honor»

21. ONU, Comité para la Eliminación de la Discriminación contra la Mujer, Recomendación General N. ${ }^{\circ} 12$ sobre «Violencia contra la mujer», $8 .^{\circ}$ período de sesiones, 1989 , espe-

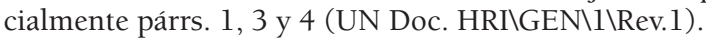


como justificación para atacar a las mujeres de la familia o darles muerte (párr. 24.r.ii) ${ }^{22}$.

Con todo, aunque el artículo 28.2 de la CEDAW establece expresamente que no se aceptará ninguna reserva de los Estados incompatible con el objeto y el propósito de la Convención, sin embargo, conforme a la Convención de Viena sobre el Derecho de los Tratados de $1969^{23}$, un buen número de los 189 Estados que hasta el momento han ratificado la Convención o se han adherido a ella han presentado numerosas reservas ${ }^{24}$ (Clark 283; Velázquez Borges 438), bien de carácter general o a específicos artículos de la CEDAW, especialmente a los artículos 2 y 16, alegando la incompatibilidad de las disposiciones de la Convención con la legislación o disposiciones legales nacionales de carácter religioso, como la sharia islámica (Amnesty International 1). Así, Malasia, Mauritania y Arabia Saudita han formulado una reserva general frente a cualquier discrepancia entre la Convención y la ley islámica ${ }^{25}$. Igualmente,

22. De conformidad con el Comité para la Eliminación de la Discriminación contra la Mujer, los actos de violencia de género no se limitan a los actos cometidos por los gobiernos o en su nombre, antes al contrario, los Estados Parte se comprometen a adoptar todas las medidas apropiadas para eliminar la discriminación contra la mujer practicada por cualesquiera personas, organizaciones o empresas, pues en virtud del Derecho internacional y de los pactos específicos de derechos humanos, los Estados también pueden ser responsables de actos privados si no adoptan medidas con la diligencia debida para impedir la violación de los derechos o para investigar y castigar los actos de violencia e indemnizar a las víctimas, ver ONU, Comité para la Eliminación de la Discriminación contra la Mujer, Recomendación General N . ${ }^{\circ} 19$ sobre «La violencia contra la mujer», 11. ${ }^{\circ}$ período de sesiones, 1992, especialmente párrs. 6, 9, 11 y 24 (UN Doc. HRI GEN\1\ Rev.1).

23. El art. 19 de la Convención de Viena sobre el Derecho de los Tratados, adoptada el 23 de mayo de 1969 y entrada en vigor el 27 de enero de 1969, permite a los Estados formular reservas en el momento de firmar, ratificar, aceptar, o aprobar un Tratado o de adherirse al mismo, con el objetivo de excluir o modificar los efectos jurídicos de determinadas previsiones del Tratado, salvo que la reserva esté prohibida por el Tratado, que el Tratado disponga que únicamente pueden hacerse determinadas reservas, entre las que no figura la reserva de que se trate o que, en los casos no previsto anteriormente, la reserva sea incompatible con el objeto y el fin del tratado. Asimismo, el art. 20 de la Convención de Viena sobre la Sucesión de Estados en materia de tratados, de 23 de agosto de 1978, y entrada en vigor el 6 de noviembre de 1996, se incluye la posibilidad de formular la reserva en el momento en que el Estado hace una notificación de sucesión de un Tratado.

24. Las reservas presentadas por los Estados a la Convención pueden consultarse en United Nations Entity for Gender Equality and the Empowerment of Women, Convention on the Elimination of All Forms of Driscrimination against Women, Reservations to CEDAW, <http://www.un.org/womenwatch/daw/cedaw/reservations.htm>, consultado 22-05-2016.

25. Ver ONU, Convención sobre la Eliminación de todas las formas de discriminación contra la mujer, Declaraciones, reservas, objeciones y notificaciones de retirada de reservas relacionadas con la Convención sobre la eliminación de todas las formas de discriminación 
diversos Estados han presentado reservas conjuntamente a los arts. 2 y 16 al considerar que son incompatibles con los preceptos de la sharia islámica, como es el caso de Bahréin, Bangladesh, Egipto, Marruecos y Singapur. Y, finalmente, algunos Estados, como Maldivas, Kuwait y Quatar, se reservan la aplicación del todo el art. 16 o de algunos de sus apartados si son contrarios a la ley islámica ${ }^{26}$.

Sin duda, como han puesto de manifiesto las numerosas objeciones formuladas por diversos Estados ${ }^{27}$, este tipo de reservas que supeditan la aplicación de la Convención a la ley islámica resultan incompatibles con el propósito de la Convención y menoscaban su eficacia, impidiendo al Comité de la CEDAW evaluar los progresos realizados por los Estados en la aplicación de la Convención, de ahí que el Comité haya instando en varias ocasiones a los Estados a retirarlas. Así, ya en las Recomendación General N. ${ }^{\circ}$ (1987) del Comité para la Eliminación de la Discriminación contra la Mujer relativa a las «Reservas», se manifiesta una razonable preocupación por el considerable número de reservas presentadas por los Estados que parecen incompatibles con el objeto y finalidad de la Convención, instándose a los Estados a que vuelvan a examinarlas con miras a retirarlas ${ }^{28}$. Igualmente, en la Recomendación N. ${ }^{\circ} 20$ (1992) del Comité para la Eliminación de la Discriminación contra la Mujer relativa a las «Reservas formuladas en relación con la Convención», el Comité recuerda la decisión de la Cuarta Reunión de los Estados parte sobre las reservas formuladas en relación con la Convención conforme al art. 28.2,

contra la mujer, Reunión de los Estados Parte en la Convención, Decimosexta reunión, New York, 28 de junio de 2010, pp. 25, 16, 18 (UN Doc. CEDAW/SP/2010/2).

26. Ver ONU, Convención sobre la Eliminación de todas las formas de discriminación contra la mujer, Declaraciones, reservas, objeciones y notificaciones de retirada de reservas relacionadas con la Convención sobre la eliminación de todas las formas de discriminación contra la mujer, Reunión de los Estados Parte en la Convención, Decimosexta reunión, New York, 28 de junio de 2010, pp. 9, 10, 14, 16, 20, 24-25 (UN Doc. CEDAW/ $\mathrm{SP} / 2010 / 2$ ).

27. Frente a la reserva general formulada por Arabia Saudita y Mauritania, que específicamente sujeta la aplicación de la Convención a la sharia se han presentado objeciones por numerosos países como Alemania, Austria, Dinamarca, España, Finlandia, Francia, Irlanda, Noruega, Países Bajos, Portugal, Reino Unido e Irlanda del Norte y Suecia, las objeciones presentadas por los Estados pueden consultarse en United Nations Entity for Gender Equality and the Empowerment of Women, Convention on the Elimination of All Forms of Driscrimination against Women, Declarations, Reservtions and Objections to CEDAW, <http://www.un.org/womenwatch/daw/cedaw/reservations.htm>, consultado 22-05-2016.

28. ONU, Comité para la Eliminación de la Discriminación contra la Mujer, Recomendación General N. ${ }^{\circ} 4$ sobre «Reservas», $6 .^{\circ}$ período de sesiones, 1987 (UN Doc. HRI $\backslash G E N \backslash 1 \backslash$ Rev.1).

Feminismo/s 28, diciembre 2016, pp. 91-132 
recomendando que, en relación con los preparativos de la Conferencia Mundial de Derechos Humanos de 1993, los Estados plateen la cuestión de la validez y los efectos jurídicos de las reservas formuladas en relación con reservas respecto de otros tratados de derechos humanos, que vuelvan a examinar esas reservas con vistas a reforzar la aplicación de todos los tratados de derechos humanos y que consideren la posibilidad de introducir un procedimiento para la formulación de reservas en relación con la Convención comparable a los de otros tratados de derechos humanos ${ }^{29}$.

Asimismo, en la Recomendación General N. ${ }^{\circ} 21$ (1994) del Comité para la Eliminación de la Discriminación contra la Mujer relativa a «La igualdad en el matrimonio y en las relaciones familiares», el Comité observa con alarma el número de Estados parte que han formulado reservas respecto del art. 16 de la Convención en su totalidad o en parte, especialmente cuando también han formulado reservas respecto del art. 2, aduciendo que la observancia del artículo puede estar en contradicción con una visión comúnmente percibida de la familia basada en creencias culturales o religiosas que mantienen una creencia en la estructura patriarcal de la familia que sitúa al padre, al esposo o al hijo varón en situación favorable, empeorando notablemente el lugar de la mujer en la familia, instando el Comité a los Estados a desalentar decididamente toda noción de desigualdad entre la mujer y el hombre que sea afirmada por las leyes, el derecho religioso o privado o por las costumbres y a retirar las reservas al artículo $16^{30}$.

Cuatro años más tarde, en 1998, el Comité para la Eliminación de la Discriminación contra la Mujer adopta una «Declaración relativa a las reservas a la Convención sobre la eliminación de todas las formas de discriminación contra la mujer», en la que asegura que las reservas de los Estados menoscaban la eficacia de la Convención que tiene por objeto poner fin a toda discriminación contra la mujer, contribuyendo a perpetuar las desigualdades entre mujeres y hombres, afirmando expresamente que «ni las prácticas tradicionales, religiosas o culturales ni las leyes y políticas nacionales incompatibles con la Convención pueden justificar la violación de las disposiciones de la Convención», instando a los Estados a examinar las limitaciones impuestas por los Estados al pleno cumplimiento de los principios de la Convención

29. ONU, Comité para la Eliminación de la Discriminación contra la Mujer, Recomendación General N. ${ }^{\circ} 20$ sobre «Reservas formuladas en relación con la Convención», 11..$^{\circ}$ período de sesiones, 1992, párr. 2 (UN Doc. HRI GEN $\backslash 1 \backslash$ Rev.1).

30. ONU, Comité para la Eliminación de la Discriminación contra la Mujer, Recomendación General N. ${ }^{\circ} 21$ sobre «La igualdad en el matrimonio y en las relaciones familiares», $13 .{ }^{\circ}$

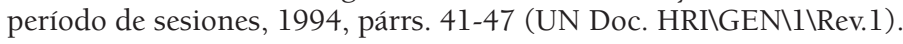


como resultado de la formulación de reservas y a su retirada por los Estados, especialmente las relativas a los artículos 2 y $16^{31}$.

Por todo, en la Recomendación General N. ${ }^{\circ} 28$ (2010) del Comité para la Eliminación de la Discriminación contra la Mujer relativa a «Las obligaciones básicas de los Estados parte de conformidad con el artículo 2 de la Convención sobre la Eliminación de todas las Formas de Discriminación contra la Mujer», el Comité señala que el art. 2 encarna la verdadera esencia de la obligaciones de los Estados parte, de ahí que las reservas al artículo 2 o a sus subpárrafos son, en principio, incompatibles con el objeto y el propósito de la Convención y por consiguiente inadmisibles de conformidad con el art. 28.2. En su virtud, el Comité afirma que el hecho de que un Estado parte haya formulado una reserva al art. 2 o a sus subpárrafos no exime al Estado de cumplir con sus otras obligaciones en virtud del Derecho internacional, por lo que las leyes nacionales, incluidas las leyes religiosas y consuetudinarias, nunca se pueden utilizar para justificar el incumplimiento de las obligaciones internacionales de los Estados, como no establecer las sanciones penales adecuadas en caso de violencia contra las mujeres en los llamados «crímenes de honor», por lo que los Estado parte deberían proceder a retirar tales reservas ${ }^{32}$.

\subsection{La ineludible obligación de los Estados de eliminar las prácticas culturales y religiosas perjudiciales, incluidos los «crímenes de honor»}

En la Declaración sobre la eliminación de la violencia contra la mujer (DEVAW por sus siglas en inglés), adoptada por la Asamblea General el 20 de diciembre de 1993, se afirma que la violencia contra la mujer constituye una violación de los derechos humanos y las libertades fundamentales e impide total o parcialmente a la mujer gozar de dichos derechos y libertades, se define la violencia contra la mujer como «todo acto de violencia basado en la pertenencia al sexo

31. Como señala el Comité, el efecto de la formulación de reservas a la Convención sobre la eliminación de todas las formas de discriminación contra la mujer puede ser doble. El Estado que formula una reserva está indicando no estar dispuesto a acatar una norma aceptada de derechos humanos. Al mismo tiempo, está garantizando la perpetuación de la desigualdad entre la mujer y el hombre a nivel nacional, ver ONU, Asamblea General, Informe del Comité para la Eliminación de la Discriminación contra la Mujer (Períodos de sesiones $18 .^{\circ}$ y $19 .{ }^{\circ}$ ), Asamblea General, Documentos Oficiales, Quincuagésimo tercer período de sesiones, Suplemento N. ${ }^{\circ}$ 38, especialmente pp. 52-55 (UN Doc. A/53/38/REV.1).

32. ONU, Comité para la Eliminación de la Discriminación contra la Mujer, Recomendación General N. ${ }^{\circ} 28$ relativa a «Las obligaciones básicas de los Estados partes de conformidad con el artículo 2 de la Convención sobre la eliminación de todas las formas de discriminación contra la mujer», $47 .^{\circ}$ período de sesiones, 16 de diciembre de 2010 , párrs. 33, 41 y 42.

Feminismo/s 28, diciembre 2016, pp. 91-132 
femenino que tenga o pueda tener como resultado un daño o sufrimiento físico, sexual o psicológico para la mujer, así como las amenazas de tales actos, la coacción o la privación arbitraria de la libertad, tanto si se producen en la vida pública como en la vida privada», y se insiste en el concepto de «diligencia debida», referido al deber de los Estados de prevenir, investigar y castigar todo acto de violencia contra la mujer, ya sea perpetrado por el Estado o por particulares, instándose a los Estados a condenar la violencia contra la mujer y a no invocar ninguna costumbre, tradición o consideración religiosa para eludir su obligación de procurar eliminarla ${ }^{33}$.

Igualmente, en la Plataforma de Acción de Beijing, aprobada en el marco de la IV Conferencia Mundial sobre la Mujer, celebrada en Beijing del 4 al 15 de septiembre de 1995, que dispone las bases para lograr el ejercicio de los derechos y libertades de las mujeres en igualdad de condiciones con los hombres en todas las esferas, política y pública, económica, social y cultural, establece como una de las esferas principales de acción la violencia contra la mujer, instándose a los Estados a adoptar medidas integrales para prevenir y eliminar la violencia contra la mujer, especialmente, condenar la violencia contra la mujer y abstenerse de invocar ninguna costumbre, tradición o consideración de carácter religiosa o cultural para eludir las obligaciones con respecto a su eliminación que figuran en la Declaración sobre la Eliminación de la Violencia contra la Mujer ${ }^{34}$.

Desde Beijing, la violencia contra la mujer, incluidos los llamados «crímenes de honor» se ha abordado en numerosas Resoluciones de la Asamblea General, como la serie de Resoluciones sobre la Eliminación de todas las formas de violencia contra la mujer, incluidos los delitos indicados en el documento final del vigésimo tercer período extraordinario de sesiones de la Asamblea General, titulado «La mujer en el año 2000: igualdad entre los géneros, desarrollo y paz

33. La Declaración sobre la Eliminación de la violencia contra la Mujer establece un amplio conjunto de normas de Derecho internacional para la protección de la mujer contra la violencia, reconoce la violencia contra la mujer como un obstáculo para el logro de la igualdad y una manifestación de las relaciones de poder históricamente desiguales entre hombres y mujeres, así como una violación de las libertades fundamentales, incluida la prohibición de la tortura, ver ONU, Declaración sobre la eliminación de la violencia contra la mujer, A/RES/48/104, de 20 de diciembre de 1993, especialmente arts. 1-4. Sobre la norma de la diligencia debida de los Estados para erradicar la violencia contra la mujer, ver ONU, Informe de la Relatora Especial sobre la violencia contra la mujer, sus causas y consecuencias, sobre «La norma de la debida diligencia como instrumento para la eliminación de la violencia contra la mujer», 10 de enero de 2006 (UN Doc. E/ CN.4/2006/61).

34. ONU, Informe de la IV Conferencia Mundial sobre la Mujer, Beijing, 4 a 15 de septiembre de 1995, New York, 1995, especialmente párrs. 124 y ss. (UN Doc. A/CONF.177/20/Rev.1).

Feminismo/s 28, diciembre 2016, pp. 91-132 
para el siglo XXI» (Resoluciones A/RES/59/167, de 20 de diciembre de 2004; A/ RES/57/181, de 18 de diciembre de 2002; y A/RES/55/68, de 4 de diciembre de 2000), en las que la Asamblea expresa su preocupación por la persistencia de diversas formas de violencia y delitos contra la mujer, incluidos los crímenes cometidos en nombre del «honor», instándose a los Estados a que adopten las medidas preventivas necesarias para la eliminación de todas las formas de violencia contra la mujer ${ }^{35}$.

Igualmente, en las Resoluciones relativas a la «Intensificación de los esfuerzos para eliminar todas las formas de violencia contra la mujer» (Resoluciones A/RES/69/147, de 18 de diciembre de 2014; A/RES/67/144, de 20 de diciembre de 2012; A/RES/65/187, de 21 de diciembre de 2010; A/RES/64/137, de 18 de diciembre de 2009; A/RES/63/155, de 18 de diciembre de 2008; A/RES/62/133, de 18 de diciembre de 2007; A/RES/61/143, de 19 de diciembre de 2006), se reconoce que todos los derechos humanos son universales, indivisibles e interdependientes y están relacionados entre sí y que la comunidad internacional debe tratar los derechos humanos en forma global y de manera justa y equitativa, en pie de igualdad y dándoles a todos el mismo peso, se afirma que, si bien debe tenerse en cuenta la importancia de las particularidades nacionales y regionales y de los diversos patrimonios históricos, culturales y religiosos, los Estados tienen el deber, sea cual fuere su sistema político, económico y cultural, de promover y proteger todos los derechos humanos y las libertades fundamentales, destacándose la importancia de que los Estados condenen enérgicamente la violencia contra la mujer y se abstengan de invocar ninguna costumbre, tradición o consideración de carácter religioso para eludir sus obligaciones con respecto a su erradicación que figuran en la Declaración sobre la Eliminación de la Violencia contra la mujer ${ }^{36}$.

Asimismo, durante estos años se ha prestado especial atención a las formas específicas de violencia contra la mujer derivadas de prácticas nocivas o perjudiciales que, como la mutilación genital femenina, el matrimonio forzado y los

35. Estas Resoluciones han originado varios informes del Secretario General con idéntico rótulo, ver Informes A/59/281, de 20 de agosto de 2004 y A/57/171, de 2 de julio de 2002. La Asamblea General también ha adoptado varias Resoluciones relativas a «Estudios a fondo sobre todas las formas de violencia contra la mujer» (Resoluciones 60/136, de 16 de diciembre de 2005 y 58/185, de 22 de diciembre de 2003), que también han generado diversos informes del Secretario General (Informes A/61/122/Add.1, de 25 de julio de 2006; y A/60/211, de 10 de agosto de 2005).

36. Estas Resoluciones han generado una serie de informes del Secretario General bajo el mismo título, ver Informes A/67/220, de 1 agosto de 2012; A/65/208, de 2 de agosto de 2010; A/64/151, de 17 de julio de 2009; A/63/214, de 4 de agosto de 2008; y A/62/201, de 3 de agosto de 2007. 
«crímenes de honor», son consecuencia de tradiciones culturales y religiosas discriminatorias que regulan la posición subordinada de la mujer en la familia, la comunidad y la sociedad. Así, en las diversas Resoluciones de la Asamblea General de 1997 a 2001 relativas a la «Eliminación de las prácticas tradicionales o consuetudinarias que afectan a la salud de la mujer y la niña», se insta a los Estados a que aprueben y apliquen leyes y políticas nacionales que prohíban las prácticas tradicionales y consuetudinarias perjudiciales para la salud de la mujer y la niña, adoptando medidas apropiadas contra los responsables y estableciéndose mecanismos específicos encargados de la aplicación y vigilancia de la legislación, el cumplimiento de la ley y las políticas nacionales ${ }^{37}$.

De igual manera, en el Suplemento del Manual de Legislación sobre Violencia contra la Mujer referido a las «Prácticas perjudiciales», publicado por la División para el Adelanto de la Mujer de las Naciones Unidas en 2011, se afirma que las prácticas perjudiciales son el resultado de la desigualdad entre los géneros y de normas sociales, culturales y religiosas y tradiciones discriminatorias que regulan la posición de la mujer en la familia, la comunidad y la sociedad y controlan la libertad de las mujeres, incluida su sexualidad, incluyéndose un exhaustivo catálogo de recomendaciones dirigidas a los Estados para que armonicen sus legislaciones y regulen de forma unitaria a fin de evitar la reproducción de prácticas perjudiciales contra la mujer, recomendándoseles, especialmente, que revisen la Constitución para garantizar que donde coexistan múltiples sistemas jurídicos, todos ellos guarden conformidad con los derechos humanos y las normas de igualdad entre mujeres y hombres y no supongan una desventaja para las mujeres víctimas/supervivientes de la violencia, que promulguen una legislación exhaustiva sobre prácticas perjudiciales, bien en forma de leyes específicas o en el marco de leyes más generales sobre la violencia contra la mujer, que establezcan el principio de extraterritorialidad en relación con las prácticas perjudiciales y se contemple la extradición de los autores de las prácticas perjudiciales para que puedan ser juzgados, así como que se prevean sanciones eficaces contra quienes toleren cualquier práctica o participe en ella, incluidos los dirigentes religiosos, tradicionales, comunitarios y tribales y los

37. Ver las Resoluciones de la Asamblea General 56/128, de 19 de diciembre de 2001; 54/133, de 17 de diciembre de 1999; 53/117, de 9 de diciembre de 1998; y 52/99, de 12 de diciembre de 1997. Realmente, desde la década de 1950 diversos órganos de las Naciones Unidas se han ocupado de las prácticas perjudiciales para la salud y el bienestar de la mujer y la niña, intensificándose los esfuerzos a partir de la década de 1990, para una sinopsis ver el Informe del Secretario General A/53/354, de 10 de septiembre de 1998, sobre «Prácticas tradicionales o consuetudinarias que afectan a la salud de la mujer y la niña»; ver igualmente los Informes posteriores del Secretario General sobre el mismo tema A/56/316, de 22 de agosto de 2001 y A/58/169, de 18 de julio de 2003.

Feminismo/s 28, diciembre 2016, pp. 91-132 
profesionales de la salud, los proveedores de servicios sociales y los trabajadores del sistema educativo (United Nations 2011, 11-15).

En relación con los «crímenes de honor», en el Suplemento del Manual de Legislación sobre violencia contra la Mujer se recomienda específicamente que en la legislación se incluya una definición amplia de los «crímenes de honor» que abarque toda la gama de actos de discriminación y violencia cometidos en nombre del «honor» contra las mujeres para controlar sus opciones vitales, movimientos, conducta sexual y su reputación, debiendo tipificarse como delitos específicos y distintos los dirigidos a: cometer, facilitar, apoyar o tolerar «crímenes de honor»; inducir a menores a cometer «crímenes de honor»; incitar a mujeres a suicidarse o a prenderse fuego en nombre del «honor»; y cometer crímenes en nombre del «honor» haciéndolos pasar por accidentes. Asimismo, se recomienda que en la legislación se despenalicen todos los actos tipificados como delito respecto del adulterio, pues en muchos países el adulterio sigue siendo todavía un delito punible con penas muy severas, incluida la lapidación, y con frecuencia la legislación en materia de adulterio se aplica de forma perjudicial para la mujer, tanto en los casos en los que la legislación procesal religiosa hace que resulte imposible de demostrar el adulterio cometido por un varón, como en aquellos en los que las mujeres violadas que no pueden demostrarlo son acusadas de adúlteras. Igualmente, se recomienda que se suprima de la legislación penal toda reducción o exoneración de las penas impuestas basadas en el «honor $»^{38}$ (United Nations 2011, 20-23).

Y tres años más tarde, en la Recomendación General N. ${ }^{\circ} 31$ del Comité para la Eliminación de la Discriminación contra la Mujer y en la Observación General N. ${ }^{\circ} 18$ del Comité sobre los Derechos del Niño relativa a «Las prácticas nocivas», adoptadas de manera conjunta el 14 de noviembre de 2014, se afirma que este tipo de prácticas se fundamentan en la discriminación hacia la mujer y se justifican a menudo mediante la invocación de valores socioculturales y religiosos, constituyendo una negación de la dignidad o integridad de la persona y una violación de los derechos humanos y libertades fundamentales consagrados en la Convención para la Eliminación de la Discriminación contra la Mujer y en la Convención sobre los Derechos del Niño, comportando

38. Como se señala en el Suplemento del Manual, diversos países siguen manteniendo en sus Códigos Penales disposiciones que reducen la sentencia aplicable por asesinato en los casos en los que el autor ha sido testigo de adulterio o se demuestra sin lugar a dudas que la víctima había cometido adulterio, incluso las legislaciones de algunos países siguen teniendo vigentes disposiciones referidas específicamente al «honor» como eximente o motivo para reducir la sentencia en los casos de asesinato, siendo fundamental suprimir esas disposiciones para que los «crímenes de honor» se castiguen con la misma severidad que otros delitos de la misma gravedad (United Nations 2011, 22-23).

Feminismo/s 28, diciembre 2016, pp. 91-132 
consecuencias negativas, incluidos daños físicos, psicológicos, económicos y sociales o violencia y limitaciones a su capacidad para participar plenamente en la sociedad y desarrollar todo su potencial, destacándose entre sus manifestaciones, la mutilación genital femenina, el matrimonio infantil o forzado y los delitos cometidos por motivos de «honor ${ }^{39}$, instándose a los Estados a prohibir de manera explícita por ley y sancionar debidamente o tipificar como delito las prácticas nocivas de acuerdo con la gravedad de la infracción y el daño ocasionado, establecer medios de prevención, protección, recuperación, reintegración y reparación para las víctimas, y a combatir la impunidad por la comisión de prácticas nocivas, debiendo la legislación dirigida a eliminar las prácticas nocivas establecer las medidas adecuadas de presupuestación, aplicación y de carácter coercitivo, recomendándose igualmente a los Estados que elaboren y aprueben programas de concienciación integrales para cuestionar y cambiar las actitudes, tradiciones y costumbres culturales y sociales que son la causa subyacente de las formas de conducta que perpetúan tales prácticas nocivas ${ }^{40}$.

Y en relación con los crímenes cometidos por motivos de «honor», la Recomendación afirma expresamente que son actos de violencia que se cometen de manera desproporcionada, aunque no exclusiva, contra niñas y mujeres porque los familiares consideran que un determinado comportamiento supuesto, subjetivo o real traerá la deshonra a la familia o la comunidad, incluyéndose, entre otros comportamientos, mantener relaciones sexuales antes de

39. Entre estas prácticas se incluyen también el abandono de las niñas (vinculado al trato y la atención preferentes que se prestan a los niños varones), exámenes de virginidad y prácticas conexas, castigo corporal, ritos iniciáticos violentos, prácticas relativas a la viudez, acusaciones de brujería, infanticidio e incesto, ver ONU, Recomendación General núm. 31 del Comité para la Eliminación de la Discriminación contra la Mujer y Observación General núm. 18 del Comité de los Derechos del Niño sobre «Las prácticas nocivas», adoptadas de manera conjunta, 14 de noviembre de 2014, especialmente párr 9 (UN Doc. CEDAW/C/GC/31/CRC/C/GC/18).

40. En el ámbito legislativo, los Comités recomiendan que los Estados parte en las Convenciones aprueben o enmienden la correspondiente legislación para afrontar y eliminar con eficacia las prácticas nocivas, debiendo garantizar, especialmente que la legislación cumpla totalmente con las obligaciones pertinentes establecidas en la Convención sobre la Eliminación de Todas las Formas de Discriminación contra la Mujer y la Convención sobre los Derechos del Niño y otras normas internacionales de derechos humanos que prohíben las prácticas nocivas y que dicha legislación tenga prioridad sobre las leyes consuetudinarias, tradicionales o religiosas que permiten, consienten o establecen cualquier tipo de práctica nociva, especialmente en países con sistemas jurídicos plurales, ver ONU, Recomendación General núm. 31 del Comité para la Eliminación de la Discriminación contra la Mujer y Observación General núm. 18 del Comité de los Derechos del Niño sobre «Las prácticas nocivas», adoptadas de manera conjunta, 14 de noviembre de 2014, especialmente párr. 55 (UN Doc. CEDAW/C/GC/31/CRC/C/GC/18).

Feminismo/s 28, diciembre 2016, pp. 91-132 
contraer matrimonio, negarse a aceptar un matrimonio arreglado, contraer matrimonio sin el consentimiento de los padres, cometer adulterio, pedir el divorcio, vestir de una manera que la comunidad considere inaceptable, trabajar fuera de casa o, en general, no ajustarse a los papeles estereotipados asignados a cada género, e incluso por haber sido víctima de violencia sexual. A pesar de constituir actos delictivos contra las mujeres, con frecuencia se aprueban y toleran los crímenes cometidos por motivos de «honor» como un medio para preservar o restablecer la integridad de normas culturales o religiosas tradicionales, aceptándose la defensa del «honor» como una circunstancia eximente o atenuante de tales conductas, lo que conduce en muchos casos a penas reducidas o incluso a la impunidad, recomendándose a los Estados derogar toda legislación, incluidas las leyes tradicionales, consuetudinarias o religiosas, que acepten la defensa del «honor» como justificación o circunstancia atenuante de la comisión de delitos por motivos de «honor» (párrs. 29-30, 55.d).

Por todo, no sorprende que, como se analiza a continuación, la Asamblea General de las Naciones Unidas haya adoptado varias Resoluciones específicas sobre una de las formas de violencia contra la mujer más extendidas derivadas de prácticas culturales y religiosas perjudiciales que vulneran sus derechos humanos y libertades fundamentales como son los «crímenes de honor».

\section{ESTÁNDARES ESPECÍFICOS ADOPTADOS PARA COMBATIR Y PREVENIR LOS «CRÍMENES DE HONOR»}

\subsection{Hacia la erradicación de los «delitos de honor» cometidos contra la mujer y la niña}

Realmente, a lo largo de los últimos años, especialmente a partir del año 2000, tanto la Asamblea General como distintos órganos intergubernamentales y especializados sobre derechos humanos del sistema de las Naciones Unidas han abordado los «crímenes de honor» cometidos contra las mujeres en sus resoluciones, comentarios, recomendaciones generales e informes y en los exámenes, observaciones y comentarios finales de los informes de los Estados parte. Así, en la Observación General No. 28 del Comité de Derechos Humanos, de 29 de marzo de 2000, sobre «La igualdad de derechos entre hombres y mujeres (artículo 3)», en la que se analizan los importantes efectos que tiene el artículo 3 del PIDCP en el efectivo ejercicio por las mujeres de los derechos humanos amparados por el Pacto, el Comité señala expresamente que los Estados parte deben cerciorarse de que no se utilicen actitudes tradicionales, históricas, religiosas o culturales como pretexto para justificar la vulneración del derecho 
de la mujer a la igualdad ante la ley y al disfrute en condiciones de igualdad de todos los derechos previstos en el Pacto, debiendo presentar información adecuada sobre los aspectos de la tradición, la historia, las prácticas culturales y las actitudes religiosas que comprometan o puedan prometer el cumplimiento del art. 3 e indicar las medidas que han adoptado o se proponen adoptar para su eliminación, señalándose expresamente que los «crímenes de honor» no castigados constituyen una violación grave del Pacto, especialmente de los arts. 6,14 y 26 , y que las leyes que imponen sanciones más severas a las mujeres que a los hombres en casos de adulterio o de otros delitos violan asimismo el requisito de la igualdad de trato ${ }^{41}$.

Asimismo, en el ámbito de la Comisión de Derechos Humanos, en el Informe de la Relatora Especial sobre las ejecuciones extrajudiciales, sumarias o arbitrarias, de 23 de enero de 2000, la Relatora Especial expone con detenimiento que ha recibido noticias de asesinatos de mujeres cometidos por cuestiones de «honor» en diversos países, fundamentalmente en los que la mayor parte de la población es musulmana, cuyos autores son en su mayoría hombres de la familia de la mujer asesinada que no reciben castigo o bien son condenados a penas reducidas con la justificación de que han defendido el «honor de la familia», recomendándose a los Estados llevar a la justicia a los autores de tales crímenes, adoptar las medidas legislativas que garanticen que estos asesinatos no reciban tratamiento discriminatorio favorable de conformidad con la ley y no internar en las cárceles o en centros de detención a las mujeres víctimas de asesinatos por cuestiones de «honor» ${ }^{42}$. En su virtud, en la Resolución 2000/31 de la Comisión de Derechos Humanos, de 20 de abril de 2000, sobre «Ejecuciones extrajudiciales, sumarias o arbitrarias», la Comisión toma nota con preocupación del gran número de asesinatos cometidos por

41. ONU, Comité de Derechos Humanos, Observación general núm. 28 sobre «La igualdad de derechos entre hombres y mujeres (art. 3)», 29 de marzo de 2000, especialmente párrs. 5 y 31 (UN Doc. CCPR/C/21/Rev.1/Add.10).

42. Como se expone detenidamente por la Relatora Especial en el informe, los «asesinatos por cuestiones de honor» fueron cometidos en Bangladesh, Brasil, Ecuador, India, Israel, Italia, Jordania, Marruecos, Pakistán, Reino Unido, Suecia, Turquía y Uganda. Así, en Batsail, Bangladesh, por orden de los religiosos que presidían un consejo oficioso del pueblo, una joven de 18 años fue azotada hasta que murió, por su conducta «inmoral». En un caso, en Egipto, el padre de la víctima al parecer mató a su hija, la decapitó y se paseó por las calles de la vecindad con la cabeza, gritando: «He vengado mi honor». Yen Pakistán unas 300 mujeres son asesinadas todos los años por «delitos de honor», ver ONU, Consejo Económico y Social, Comisión de Derechos Humanos, Informe de la Relatora Especial, Sra. Asma Jahangir, presentado en cumplimiento de la Resolución 1999/35 de la Comisión de Derechos Humanos sobre «Las ejecuciones extrajudiciales, sumarias o arbitrarias», de 25 de enero de 2000, párrs. 78-84 (UN Doc. E/CN.4/2000/3).

Feminismo/s 28, diciembre 2016, pp. 91-132 
cuestiones de "honor», instando a los Estados a que investiguen tales asesinatos sin tardanza, enjuicien a los responsables, y velen por que tales actos no sean tolerados ni sancionados por funcionarios o personal del Gobierno ${ }^{43}$. Y en la Resolución 55/111 de la Asamblea General, de 4 de diciembre de 2000, sobre «Ejecuciones extrajudiciales, sumarias o arbitrarias», la Asamblea hace un llamamiento a los gobiernos para que investiguen rápidamente y a fondo los casos de asesinatos cometidos en nombre del «honor» a fin de que los autores sean enjuiciados ante una judicatura independiente e imparcial, y para que velen por que dichos asesinatos no sean tolerados ni sancionados por funcionarios o personal del gobierno (párr. 7).

Igualmente, en el Informe de la Relatora Especial de la Comisión de Derechos Humanos (Subcomisión de Promoción y Protección de los Derechos Humanos) sobre «Prácticas tradicionales que afectan a la salud de las mujeres y las niñas», de 27 de junio de 2000, se dedica una especial atención a los «crímenes de honor», afirmándose que son una antigua práctica que subsiste en algunos países del Medio Oriente, en virtud de la cual se reconoce a los hombres el derecho a degollar a toda mujer de su familia de la cual se sospeche que ha tenido un comportamiento contrario al «honor» de la familia, aunque en muchas ocasiones los «crímenes de honor» no tienen nada que ver con el deshonor de la familia de la mujer asesinada sino con cuestiones de celos o herencias, relacionándose los casos habidos en determinados países como Jordania y Pakistán ${ }^{44}$.

Por tanto, no extraña que a finales del año 2000 la Asamblea General adopte la primera Resolución específica sobre los «crímenes de honor». En efecto, en la Resolución 55/66 de la Asamblea General, de 4 de diciembre de 2000, con el título «Hacia la eliminación de los delitos de honor cometidos

43. Ver también la Resolución de la Comisión de Derechos Humanos 2001/45, de 23 de abril de 2001, sobre «Ejecuciones extrajudiciales, sumarias o arbitrarias», párr. 7.

44. Según se expone en el informe, en el caso de Jordania las víctimas de estos crímenes son más de 20 al año, y en el caso de Pakistán, la Comisión de Derechos Humanos de Pakistán estima que entre 1998 y 1999 más de 850 mujeres fueron asesinadas en Punjab por su marido, hermano, padre $u$ otro miembro de la familia, al sospecharse que todas esas mujeres habían sido culpables de una conducta inmoral, registrándose en 1998-1999 560 casos de inmolación de mujeres por el fuego, falleciendo la mitad de las víctimas como consecuencia de quemaduras, siendo hospitalizadas más de 3.560 mujeres entre 1994 y 999 a raíz de agresiones con fuego, ácido o gasolina, ver ONU, Consejo Económico y Social, Comisión de Derechos Humanos, Subcomisión de Promoción y Protección de los Derechos Humanos, Tercer informe sobre la evolución de la situación relativa a la eliminación de las prácticas tradicionales que afectan a la salud de las mujeres y las niñas, elaborado por la Sra. Halima Embarek Warzazi en cumplimiento de la Resolución 1999/13 de la Subcomisión, 27 de junio de 2000, párrs. 69-77 (UN Doc. E/CN.4/Sub.2/2000/17). 
contra la mujer», la Asamblea afirma que los «crímenes de honor» cometidos contra la mujer son una cuestión de derechos humanos y que los Estados tienen la obligación de ejercer la diligencia debida para impedir esos delitos, investigarlos, castigar a los autores y dar protección a las víctimas, y que no hacerlo constituye una violación de los derechos humanos. Asimismo, expresa su preocupación por el hecho de que las mujeres siguen siendo víctimas de distintas formas de violencia, incluidos los «crímenes de honor» cometidos contra la mujer, que revisten formas muy diversas, y por el hecho de que algunos de sus autores consideren que tienen cierta justificación para cometer tales crímenes (párr. 1).

Para su erradicación, la Asamblea insta a los Estados a que: cumplan sus obligaciones en la materia en virtud del Derecho internacional relativo a los derechos humanos; intensifiquen su labor para prevenir y eliminar los «crímenes de honor» cometidos contra la mujer, recurriendo a medidas legislativas, educacionales, de política social y de otra índole, incluida la difusión de información, y hagan participar en las campañas de toma de conciencia, entre otros, a quienes forman la opinión pública, educadores, autoridades religiosas, jefes, líderes tradicionales y los medios de difusión; alienten apoyen y pongan en práctica medidas y programas encaminados a que los responsables de hacer cumplir la ley y de aplicar las normas, como los funcionarios de policía, los funcionarios del poder judicial y el personal sanitario, conozcan y comprendan mejor las causas y las consecuencias de los «crímenes de honor» cometidos contra la mujer; establezcan y faciliten servicios de apoyo a las víctimas de estos crímenes, brindándoles protección y servicios de apoyo psicológico, asesoramiento jurídico, rehabilitación y reinserción en la sociedad; y establezcan mecanismos institucionales para que las víctimas y otras personas puedan denunciar los «crímenes de honor» en condiciones de seguridad y confidencialidad, y reúnan y difundan información estadística sobre la perpetración de tales crímenes (párr. 4). Asimismo, la Asamblea alienta a los órganos creados en virtud de los tratados de derechos humanos que les competa a seguir teniendo en cuenta los «crímenes de honor» cometidos contra la mujer en sus actividades e informes, y solicita al Secretario General que le presente un informe al respecto, incluidas las medidas adoptadas por los Estados para eliminar los «crímenes de honor» (párrs. 5 y 6$)^{45}$.

45. Aunque varios Estados se mostraron a favor de la Resolución 55/66 de la Asamblea General, como es el caso de Canadá, Malta, Países Bajos y Suecia, sin embargo, algunos Estados formularon observaciones sobre la Resolución. Así, en opinión de Jordania la Resolución no aborda el concepto de «en un arrebato de ira», que es una característica distintiva de los crímenes pasionales, y la posibilidad de invocar ese concepto en el marco 
En cumplimiento del mandato de la Resolución 55/66 de la Asamblea General, el Secretario General presenta el Informe titulado «Hacia la eliminación de los delitos de honor cometidos contra la mujer», de 2 de julio de 2002, en el que se proporciona información sobre las medidas adoptadas por los Estados miembros y las actividades realizadas dentro del sistema de las Naciones Unidas con miras a la eliminación de los «crímenes de honor» cometidos contra la mujer. En relación con las medidas legislativas adoptadas por los Estados, en el informe se expone que, conforme a los datos facilitados por 26 Estados, la mayoría de sus sistemas jurídicos no prevén ese tipo de delitos por lo que de producirse se juzgan según el Derecho penal general, relacionándose las particularidades más relevantes ${ }^{46}$.

Por todo lo anterior, en el Informe se recomienda a los Estados penalizar toda forma de violencia contra mujeres y niñas en defensa del «honor», y castigar a quienes participan deliberadamente en actos de esa índole, a quienes los facilitan, los fomentan y amenazan con cometerlos; investigar sin tardanza, de forma imparcial y minuciosa, todo informe de violencia ejercida contra la mujer por cuestiones de «honor», documentar y tomar medidas judiciales efectivas al respecto; adoptar todas las medidas necesarias a fin de evitar los actos de violencia de que son objeto las mujeres por estos motivos; y en los países con comunidades de inmigrantes, ofrecer protección a las víctimas y a las posibles víctimas en relación con los procedimientos de asilo e inmigración. Asimismo, los Estados deben brindar capacitación especial y recursos al personal encargado del cumplimiento de la ley, incluidos los magistrados y juristas, a fin de atender de manera imparcial y efectiva las denuncias de violencia contra la mujer, en general, y, en particular, las que implican cuestiones de «honor», y proteger a las mujeres y niñas que corren peligro de sufrir tal violencia,

de distintos sistemas jurídicos, defendiendo que el tema y el título de la Resolución 55/66 debía haberse limitado a los «delitos de honor» premeditados, ver ONU, Asamblea General, Informe del Secretario General relativo a «Hacia la eliminación de los delitos de honor cometidos contra la mujer», 2 de julio de 2002, párrs. 14-16 (UN Doc. A/57/169).

46. Así, Jordania informó que sus leyes no tenían previstos los «delitos de honor cometidos contra la mujer», ya que esos delitos, que se cometían en el seno de la familia, se trataban en el capítulo del Código Penal relativo a delitos graves y delitos menos graves contra la persona. Y Turquía señaló que en algunas regiones, donde todavía predominaba la forma de vida tradicional, el concepto del «honor» se asociaba al cuerpo de la mujer y esa mentalidad servía de pretexto para la comisión de «delitos de honor» contra ella, de ahí que en el Código Penal turco estaban previstas penas reducidas para «delitos de honor», que también se denominaban «delitos de tradición», ver ONU, Asamblea General, Informe del Secretario General relativo a «Hacia la eliminación de los delitos de honor cometidos contra la mujer», 2 de julio de 2002, especialmente párrs. 3-5 (UN Doc. A/57/169). 
en tanto se respetan sus derechos humanos. Y, finalmente, en el informe se considera que las campañas de sensibilización, información y educación en que participen, entre otros, dirigentes religiosos y comunitarios, tendentes a cambiar estereotipos sociales en el comportamiento de mujeres y hombres son esenciales para prevenir y eliminar la violencia contra mujeres y niñas por cuestiones de «honor», debiendo alentarse a los medios de comunicación a que participen activamente (párrs. 31-34).

A finales de este año se adopta una segunda Resolución de la Asamblea General sobre los «crímenes de honor». Así, en la Resolución 57/179 de la Asamblea General, de 18 de diciembre de 2002, con el título «Hacia la erradicación de los delitos de honor cometidos contra la mujer», la Asamblea afirma que estos delitos son incompatibles con todos los valores religiosos y culturales y expresa su preocupación por el hecho de que las mujeres sigan siendo víctimas de «crímenes de honor» en todas las regiones del mundo, y por los casos en que los autores no son procesados ni castigados (párr. 2). Para su erradicación, la Asamblea insta a los Estados a que cumplan sus obligaciones en la materia en virtud de los instrumentos internacionales de derechos humanos y pongan en práctica la Declaración y Plataforma de Acción de Berijing, a que investiguen prontamente y a fondo, enjuicien eficazmente y documenten los casos de «crímenes de honor» cometidos contra la mujer y castiguen a los autores, y a que intensifiquen sus esfuerzos a fin de de que se cobre más conciencia de la necesidad de prevenir y erradicar los «crímenes de honor» cometidos contra la mujer, para modificar actitudes y comportamientos. Asimismo, la Asamblea insta a los Estados a que alienten, apoyen y pongan en práctica medidas y programas encaminados a conocer y comprender mejor las causas y las consecuencias de los «crímenes de honor» cometidos contra la mujer, incluida la capacitación de los responsables de hacer cumplir la ley, y a que establezcan servicios de apoyo para atender a las necesidades de quienes hubieran sido o pudieran ser víctimas de tales delitos, y a que reúnan y difundan información estadística sobre la incidencia de los mismos (párr. 3).

Finalmente, la Asamblea exhorta a los órganos creados en virtud de los tratados de derechos humanos que corresponda, que sigan teniendo en cuenta la cuestión de los "crímenes de honor», y a la Comisión de la Condición Jurídica y Social de la Mujer a que examine esta cuestión en su $47 .^{\circ}$ período de sesiones (2003), en relación con el tema prioritario «Los derechos humanos de la mujer y la eliminación de todas las formas de violencia contra la mujer y la niña, tal como se definieron en la Plataforma de Acción de Beijing y en el documento final del período extraordinario de sesiones de la Asamblea General titulado 'La mujer en el año 2000: igualdad entre los géneros, desarrollo y paz para el 
siglo XXI'» (párr. 4) ${ }^{47}$.Y, por último, pide al Secretario General que incluya en su próximo informe sobre la eliminación de la violencia contra la mujer un informe sustantivo sobre el tema de la resolución que esté basado en todos los datos disponibles y contengan un análisis de las causas básicas de los «crímenes de honor», con datos estadísticos e información sobre las iniciativas adoptadas por los Estados (párr. 6).

Atendiendo a los requerimientos de la Asamblea General, un año más tarde, en el informe de la Relatora Especial de la Comisión de Derechos Humanos sobre las ejecuciones extrajudiciales, sumarias o arbitrarias, de 22 de diciembre de 2003, se informa con detenimiento de los informes recibidos sobre los casos de asesinatos por razones de «honor» que habían contado con la aprobación o el apoyo del Estado o en los que éste había permitido por su inactividad una impunidad de hecho para quienes los habían perpetrado, analizando especialmente el caso de Pakistán, respecto del que se había transmitido una comunicación relativa al asesinato de 208 mujeres, y el de las mujeres condenadas a muerte por adulterio en Nigeria, como el célebre caso de Amina Lawal, condenada a muerte por lapidación al ser declarada culpable de adulterio al haber dado a luz un hijo fuera del matrimonio, recordando la Relatora Especial que los Estados están obligados a proteger el derecho a la vida de todas las mujeres adoptando todas las disposiciones adecuadas, incluidas medidas legislativas, así como derogando las disposiciones normativas, los usos y prácticas que violan los derechos humanos de las mujeres, instándose a los Estados a introducir las modificaciones legislativas necesarias para que los asesinatos por razones de «honor» no reciban trato discriminatorio en Derecho, sensibilizar a la administración de justicia sobre la igualdad entre los sexos e impedir que en los correccionales y centros de detención se recluyan por la fuerza a las mujeres víctimas de asesinatos por cuestiones de «honor $»^{48}$.

47. Lamentablemente, en el $47 .^{\circ}$ período de sesiones de la Comisión de la Condición Jurídica y Social de la Mujer, que tuvo lugar del 3 al 14 y el 15 de marzo de 2003, no se adoptaron conclusiones convenidas que contuvieran un análisis del tema prioritario y un conjunto de recomendaciones concretas para los gobiernos, los organismos intergubernamentales y otras instituciones que se aplicasen en el nivel internacional, nacional, regional y local, sobre el tema prioritario relativo a los derechos humanos de las mujeres y la eliminación de todas las formas de violencia contra la mujer y la niña, ver ONU, Comisión de la Condición Jurídica y Social de la Mujer, Informe sobre el $47 .^{\circ}$ período de sesiones ( 3 a 14 y 25 de marzo de 2003), Consejo Económico y Social, Documentos Oficiales, 2003, Suplemento No. 7, Anexo II, pp. 55-58 (UN Doc. E/2003/27).

48. ONU, Consejo Económico y Social, Comisión de Derechos Humanos, Informe de la Relatora Especial, Asma Jahangir, sobre las ejecuciones extrajudiciales, sumarias o arbitrarias, de 22 de diciembre de 2003, párrs. 66-71 y 96.8 (UN Doc. E/CN.4/2004/7). 
En cumplimiento del mandato de la Resolución 57/179 de la Asamblea General, en el Informe del Secretario General sobre la «Violencia contra la mujer», de 20 de agosto de 2004, se abordan de forma específica las medidas legislativas, normativas o de otra índole adoptadas por los Estados miembros a fin de combatir los crímenes cometidos contra la mujer en nombre del «honor». De las respuestas facilitadas por los Estados se concluye que en la mayoría no hay una legislación específica que abarque concretamente ese tipo de delitos, por lo que se castigan conforme a las disposiciones pertinentes del Código Penal, aunque algunos países han llevado a cabo modificaciones legislativas para reducir los casos de violencia contra la mujer en general y los «crímenes de honor» en particular. No obstante, la mayoría de los países que facilitaron información al Secretario General se refieren a diversas medidas y programas destinados a combatir los «crímenes de honor», y en el caso de los países que consideran que este fenómeno está más presente en las comunidades de inmigrantes enmarcan su acción en el contexto de las políticas de integración, formando incluso a sus funcionarios para que entiendan mejor la cuestión del «honor» en este contexto. Por todo ello, el Secretario General recomienda a los Estados que procedan a elaborar marcos legislativos integrales que tipifiquen como delito todas las formas de violencia contra la mujer y apliquen penas adecuadas para los autores, y que cuando se informe de delitos cometidos contra la mujer en nombre del «honor» se tipifiquen como tales y se sometan inmediatamente a juicio ${ }^{49}$.

Por todo lo anteriormente expuesto, a finales de 2004 la Asamblea General adopta una tercera Resolución sobre los «crímenes de honor». En efecto, en la Resolución 59/165 de la Asamblea General, de 20 de diciembre de 2004, titulada «Hacia la erradicación de los delitos de honor cometidos contra la mujer y la niña», la Asamblea General vuelve a reiterar que los Estados están obligados

49. A fecha de 14 de mayo de 2014, solamente 23 Estados habían respondido a la petición del Secretario General de facilitar información sobre la aplicación de la Resolución 57/179 de la Asamblea General, a saber, Alemania, Argentina, Austria, Azerbaiyán, Bangladesh, Colombia, Costa Rica, China, Dinamarca, Federación de Rusia, Finlandia, Irlanda, Islandia, Italia, Jordania, Kuwait, Malasia, Malta, Marruecos, México, Noruega, Paraguay, Portugal, República Árabe Siria, República de Corea y Ucrania. Diversos países informan que han adoptado medidas en el ámbito legislativo para erradicar los «delitos de honor», así en el caso de Jordania, en virtud de la Ley provisional No. 86 de 2001, todavía no promulgada, se modifica el artículo 240 del Código Penal suprimiendo el régimen de las circunstancias eximentes y sustituyéndolo por el de las circunstancias atenuantes. Asimismo, diversos países europeos informan de la adopción de medidas y programas en relación con la población inmigrante, como es el caso de Países Bajos y Suecia, ver ONU, Asamblea General, Informe del Secretario General sobre la «Violencia contra la mujer», 20 de agosto de 2004, párrs. 35-45 y 65 (UN Doc. A/59/281). 
a ejercer la diligencia debida para impedir los «crímenes de honor» cometidos contra la mujer y la niña, investigarlos, castigar a los autores y dar protección a las víctimas, que no hacerlo constituye una violación de sus derechos humanos y libertades fundamentales, y que estos delitos son incompatibles con todos los valores religiosos y culturales. Para su erradicación, la Asamblea vuelve a instar a los Estados a que: cumplan sus obligaciones en virtud de los instrumentos internacionales de derechos humanos; investiguen prontamente y a fondo, enjuicien eficazmente y documenten los casos de «crímenes de honor» cometidos contra la mujer y castiguen a los autores; intensifiquen sus esfuerzos para que se cobre más conciencia de la necesidad de prevenir y erradicar los «crímenes de honor» cometidos contra la mujer, a fin de modificar actitudes y comportamientos; alienten, apoyen y pongan en práctica medidas y programas encaminados a conocer y comprender mejor las causas y las consecuencias de estos delitos, incluida la capacitación de los responsables de hacer cumplir la ley; establezcan servicios de apoyo para atender a las necesidades de quienes hubieran sido o pudieran ser víctimas de tales delitos; y que reúnan y difundan información estadística sobre la incidencia de los «crímenes de honor» (párr. 3). Finalmente, la Asamblea exhorta a los órganos correspondientes creados en virtud de los tratados de derechos humanos, cuando proceda, y a la Relatora Especial de la Comisión de Derechos Humanos sobre la violencia contra la mujer, sus causas y consecuencias, a que sigan prestando atención a esta cuestión y requiere al Secretario General que en el informe sobre la cuestión de la violencia contra la mujer que le presente en su sexagésimo período de sesiones incluya información sobre la aplicación de la Resolución 59/165 (párr. 4) ${ }^{50}$.

En cumplimiento del mandato de la Asamblea General, en el Informe del Secretario General sobre «Estudio a fondo sobre todas las formas de violencia contra la mujer», de 6 de julio de 2006, se afirma que si bien algunas de las normas y prácticas culturales empoderan a las mujeres y promueven sus derechos humanos, también es frecuente que las costumbres, las tradiciones y

50. En el último informe de la Relatora Especial de la Comisión de Derechos Humanos sobre prácticas tradicionales que afectan a la salud de las mujeres y las niñas, se incluye un apartado relativo a los delitos por cuestiones de «honor» en el que se agradece que se hayan adoptado las Resoluciones específicas sobre los «delitos de honor» contra la mujer de la Asamblea General 57/179 y 59/165, y se hace referencia a los datos aportados en el informe del Secretario General sobre violencia contra la mujer A/59/281, de 20 de agosto de 2004, ver ONU, Consejo Económico y Social, Comisión de Derechos Humanos, Noveno y último Informe sobre la evolución de la situación relativa a la eliminación de las prácticas tradicionales que afectan a la salud de las mujeres y las niñas, elaborado por la Relatora Especial, Sra. Halima Embarek Warzazi, 11 de julio de 2005, párrs. 77-81 (UN Doc. E/CN.4/Sub.2/2005/36).

Feminismo/s 28, diciembre 2016, pp. 91-132 
los valores religiosos se utilicen para justificar la violencia contra la mujer, en particular las creencias vinculadas con las «prácticas tradicionales nocivas», como los crímenes en nombre del «honor», que cometidos por lo común por un hermano, el padre, el marido u otro pariente masculino, son un medio de controlar las opciones de las mujeres, no sólo en la esfera de la sexualidad sino también en otros aspectos del comportamiento, como la libertad de circulación, de ahí que frecuentemente estos crímenes tengan una dimensión colectiva, pues la familia en su conjunto se considera lesionada por el comportamiento real o percibido de la mujer, y a menudo tengan un carácter público, contribuyendo a influir en la conducta de otras mujeres. No obstante, afirma el Secretario General que en el ámbito legislativo se han producido algunos avances, pues en Túnez se ha eliminado la reducción de la pena en casos de «homicidios de honor» y en Turquía los crímenes cometidos en nombre del «honor» son penados con prisión perpetúa ${ }^{51}$.

Pese a todo, unos años más tarde, en el Informe de la Relatora Especial de la Comisión de Derechos Humanos sobre la violencia contra la mujer, sus causas y sus consecuencias, de 1 de agosto de 2011, se sigue haciendo referencia a los «crímenes de honor», afirmándose que desde la creación de su mandato se han comunicado casos de violencia y asesinato de mujeres en nombre del «honor» en el curso de las visitas a distintos países, como Argelia, Afganistán, Irán, Países Bajos, los territorios palestinos ocupados, Pakistán, Suecia y Turquía ${ }^{52}$. Por esto no sorprende que, como se analiza a continuación, las Naciones Unidas hayan abordado recientemente los «crímenes de honor» en el marco de las medidas que deben adoptar los Estados para prevenir, investigar, perseguir y castigar el asesinato de mujeres y niñas por razones de género, incluidos los asesinatos por razones de «honor».

\subsection{La ineludible obligación de los Estados de adoptar medidas concretas contra el asesinato de mujeres y niñas por razones de «honor»}

En efecto, en el informe de la Relatora Especial sobre la violencia contra la mujer relativo a «Los homicidios de mujeres relacionados con el género», de 23 de mayo de 2012, se afirma que por tales se entiende el asesinato de mujeres y niñas por el hecho de pertenecer al sexo femenino, constituyendo

51. ONU, Asamblea General, Informe del Secretario General relativo a «Estudio a fondo sobre todas las formas de violencia contra la mujer», 6 de julio de 2006, párrs. 78, 124 303 (UN Doc. A/61/122/Add.1).

52. ONU, Asamblea General, Informe de la Relatora Especial sobre la violencia contra la mujer, sus causas y consecuencias, Rashida Manjoo, de conformidad con la Resolución 65/187 de la Asamblea General, 1 de agosto de 2011, párr. 32 (UN Doc. A/66/215). 
la manifestación más extrema de la violencia contra la mujer, que a menudo representa el acto último de un continuo de violencia, prolongado e ignorado, distinguiéndose entre las formas activas o directas de homicidio por razones de género y sus formas pasivas o indirectas, figurando entre las formas directas los asesinatos como resultado de la violencia en la pareja, asesinatos relacionados con la hechicería o brujería, asesinatos relacionados con el «honor», asesinatos relacionados con conflictos armados, asesinatos relacionados con la dote, asesinatos relacionados con la identidad de género y la orientación sexual y asesinatos relacionados con la identidad étnica o indígena ${ }^{53}$.

En relación con los homicidios de mujeres y niñas por razones de «honor», la Relatora Especial afirma que constituyen una de las más graves de las prácticas nocivas contra la mujer más extendidas, produciéndose especialmente en la amplia zona que va desde el Sáhara al Himalaya, aunque también tiene lugar en otras regiones y países con comunidades migrantes. Tales homicidios por razones de «honor» revisten muchas formas, bien el asesinato directo o la lapidación, bien se obliga a las mujeres a suicidarse tras denunciar públicamente su comportamiento, o bien se las desfigura con ácido, causándoles en muchos casos la muerte. Incluso, la Relatora manifiesta su preocupación por el fenómeno de la autoinmolación, denunciado en Afganistán y la República Islámica de Irán, consistente en que las mujeres o las jóvenes tratan de suicidarse prendiéndose fuego porque consideran que están «deshonrando» a la familia. Pese a su gravedad, la Relatora se lamenta de que los crímenes por razones de «honor» muchas veces no se denuncian, rara vez se investigan, por lo que suelen quedar impunes, y cuando son sancionados las sentencias son mucho más leves que las que se imponen por crímenes igualmente violentos sin la dimensión del «honor $»^{54}$.

Un año más tarde, en el Informe de la Relatora Especial sobre la violencia contra la mujer relativo a las "Causas, condiciones y consecuencias de la encarcelación para las mujeres», de 21 de agosto de 2013, se señala expresamente que a veces se mantiene a las mujeres en prisiones para evitar que se conviertan en víctimas de los «crímenes de honor». Asimismo, en el Informe se constata que las mujeres víctimas de delitos por razones de «honor» también encuentran problemas por la falta de programas eficaces de rehabilitación e inserción, así en

53. ONU, Asamblea General, Consejo de Derechos Humanos, Informe de la Relatora Especial sobre la violencia contra la mujer, sus causas y sus consecuencias, Sra. Rashida Manjoo, 23 de mayo de 2012, párrs. 15 y 16 (UN Doc. A/HRC/20/16).

54. ONU, Asamblea General, Consejo de Derechos Humanos, Informe de la Relatora Especial sobre la violencia contra la mujer, sus causas y sus consecuencias, la Sra. Rashida Manjoo, 23 de mayo de 2012, párrs. 43-50 (UN Doc. A/HRC/20/16). 
algunos países las mujeres no pueden volver a su casa tras ser liberadas por el miedo a la violencia que pueda cometerse contra ellas, solicitando permanecer en los centros de detención tras la fecha de su puesta en libertad por el miedo a la violencia relacionada con el «honor $»^{55}$.

Por todo lo anteriormente expuesto, no extraña que a finales de este año se apruebe la Resolución 68/191 de la Asamblea General, de 18 de diciembre de 2013, relativa a la «Adopción de medidas contra el asesinato de mujeres y niñas por razones de género», en la que se insta a los Estados a adoptar medidas de diversa índole, como la promulgación y aplicación de leyes, para poner fin a los asesinatos de mujeres y niñas por razones de género; a prevenir el asesinato de mujeres y niñas por razones de género y ofrecer protección jurídica, incluidas vías de recurso apropiadas y mecanismos de reparación e indemnización, a las víctimas de esos delitos; a poner fin a la impunidad y velar por que los autores de esos abominables delitos contra las mujeres y las niñas rindan cuentas y sean castigados, fortaleciendo la respuesta de la justicia penal ante el asesinato de mujeres y niñas por razones de género, en particular mediante la adopción de medidas para reforzar la capacidad para investigar, enjuiciar y castigar esos delitos en todas sus formas. Asimismo, se solicita al Secretario General que convoque una reunión de un grupo intergubernamental de expertos de composición abierta para examinar las formas de prevenir, investigar, enjuiciar y castigar más eficazmente el asesinato de mujeres y niñas por razones de género, con miras a formular recomendaciones concretas, basándose en las mejores prácticas actuales, en consulta con las entidades y los mecanismos de derechos humanos pertinentes de las Naciones Unidas, y a que informe a la Asamblea General en su septuagésimo período de sesiones sobre la aplicación de la Resolución ${ }^{56}$.

Para dar cumplimiento a las previsiones contenidas en la Resolución 68/191 de la Asamblea General, en las Conclusiones y Recomendaciones del Grupo de Expertos sobre el asesinato de mujeres y niñas por razones de género relativas al «El asesinato de mujeres y niñas por razones de género: prácticas prometedoras, dificultades y recomendaciones concretas», adoptadas en Bangkok del 11 al 13 de noviembre de 2014, se define el «asesinato de mujeres por razones de género» como el asesinato, tanto en público como en privado, de mujeres por

55. ONU, Asamblea General, Informe de la Relatora Especial sobre la violencia contra la mujer, sus causas y sus consecuencias, la Sra. Rashida Manjoo, de conformidad con la Resolución 65/187 de la Asamblea General, relativo a las «Causas, condiciones y consecuencias de la encarcelación para las mujeres», 21 de agosto de 2013, párrs. 21 y 75 (UN Doc. A/68/340).

56. ONU, Resolución 68/191 de la Asamblea General, de 18 de diciembre de 2013, relativa a la «Adopción de medidas contra el asesinato de mujeres y niñas por razones de género», párrs. 1-17 (UN Doc. A/RES/68/191). 
el hecho de ser mujeres, que tiene sus raíces en la discriminación por motivos de género y en las relaciones de poder desiguales entre hombres y mujeres, agravada con frecuencia por otras formas de discriminación basadas en la raza, la casta, la clase, la ubicación geográfica, la religión o las creencias, el nivel de instrucción, la capacidad y la sexualidad, así como por una tolerancia general de la violencia contra la mujer, recomendándose instar a los Estados, entre otras medidas, a adoptar un marco jurídico que ataje eficazmente los asesinatos de mujeres por razones de género, entre otras cosas, mediante la tipificación de delitos o agravantes específicos y la estipulación de la garantía de que los autores de delitos no puedan invocar atenuantes como la «pasión», la «emoción violenta», el «honor» o la «provocación» para eludir la responsabilidad penal ${ }^{57}$.

Asimismo, un año más tarde, sobre la base de las conclusiones y recomendaciones aprobadas por el Grupo de Expertos adoptadas en Bangkok y en cumplimiento del mandato de la Resolución 68/191 de la Asamblea General, en el informe del Secretario General sobre la «Adopción de medidas contra el asesinato de mujeres y niñas por razones de género», de 16 de junio de 2015, se recomienda revisar, evaluar y actualizar las leyes nacionales para prevenir eficazmente el asesinato de mujeres por razones de género, entre otras cosas, previendo determinados delitos o agravantes y reformando esas leyes para garantizar que no contengan disposiciones discriminatorias en las que se invoquen factores como la «pasión», la «emoción descontrolada», el «honor» o la "provocación», que permitan a los autores del delito eludir su responsabilidad penal ${ }^{58}$.

Finalmente, no extraña que en la reciente Resolución 70/176 de la Asamblea General, de 17 diciembre de 2015, relativa a la «Adopción de medidas contra el asesinato de mujeres y niñas por razones de género», se vuelva a instar a los Estados a que adopten diversas medidas para prevenir, investigar, perseguir y

57. Asimismo, se recomienda instar a los Estados a elaborar, con la asistencia de los organismos competentes de las Naciones Unidas, un marco que conceptualice adecuadamente una comprensión mundial respecto del asesinato de mujeres por razones de género y estudiar la posibilidad de elaborar un indicador sobre el asesinato de mujeres por razones de género como complemento de los indicadores relativos a la documentación de la prevalencia de la violencia contra la mujer, ver ONU, Oficina de las Naciones Unidas contra la Droga y el Delito (UNODC), Grupo de Expertos sobre el asesinato de mujeres y niñas por razones de género, Conclusiones y recomendaciones del grupo de expertos sobre el «Asesinato de mujeres y niñas por razones de género: prácticas prometedoras, dificultades y recomendaciones concretas», Bangkok, 11 a 13 de noviembre de 2014, párrs. 4, 48-54 (UN Doc. UNODC/CCPCJ/EG.8/2014/2).

58. ONU, Asamblea General, Informe del Secretario General sobre la «Adopción de medidas contra el asesinato de mujeres y niñas por razones de género», 16 de junio de 2015, especialmente párr. 41.c (UN Doc. A/70/93).

Feminismo/s 28, diciembre 2016, pp. 91-132 
castigar los actos de violencia contra las mujeres y las niñas, en particular el asesinato por razones de género, incluidos los asesinatos por razones de «honor», de conformidad con la legislación nacional, y actúen a todos los niveles para poner fin a la impunidad de quienes cometan esos abominables delitos contra las mujeres y las niñas; a que protejan y apoyen a las víctimas, garantizando una eficaz cooperación entre todos los organismos estatales competentes, incluidos, la judicatura, la fiscalía, los organismos encargados de hacer cumplir la ley, los servicios de salud y sociales y las autoridades locales y regionales; y a que reúnan, desglosen, analicen y comuniquen datos sobre el asesinato de mujeres y niñas por razones de género, incluidos los asesinatos por razones de «honor», de lo que deberá dar cumplida cuenta el Secretario General el próximo año, en $2017^{59}$.

\section{CONCLUSIONES. HACIA LA ADOPCIÓN DE ESTÁNDARES NORMATIVOS ESPECÍFICOS VINCULANTES PARA ERRADICAR LOS «CRÍMENES DE HONOR»: LA FUTURA CONVENCIÓN PARA LA ELIMINACIÓN DE LA VIOLENCIA CONTRA LAS MUJERES Y LAS NIÑAS}

Como refleja este estudio, a lo largo de los últimos 20 años, tanto la Asamblea General como distintos órganos intergubernamentales y especializados de las Naciones Unidas sobre derechos humanos han abordado con especial atención los crímenes cometidos en nombre del «honor» como una forma específica de violencia contra las mujer, basada en prácticas perjudiciales que son consecuencia de tradiciones culturales y religiosas arraigadas que discriminan a la mujer y violan sus derechos humanos y libertades fundamentales, definiéndose un conjunto de estándares internacionales de derechos humanos para la prevención y erradicación de tales delitos, que requiriere la adopción por los Estados de una estrategia integral, dirigida al reforzamiento de medidas jurídicas, políticas y de carácter social.

Con todo, a pesar de los avances habidos en los últimos años, sin embargo, tal marco de estándares internacionales de las Naciones Unidas carece de un instrumento jurídico vinculante específico para combatir todas las formas de

59. Asimismo, se solicita a la Oficina de las Naciones Unidas contra la Droga y el Delito que prepare, en colaboración con los Estados miembros, un estudio analítico sobre el asesinato de mujeres y niñas por razones de género a nivel mundial, en el que figuren datos desglosados sobre este fenómeno, y se solicita también al Secretario General que informe a la Asamblea General en su septuagésimo segundo período de sesiones sobre la aplicación de la Resolución, ver ONU, Resolución 70/176 de la Asamblea General, de 17 de diciembre de 2015, relativa a la «Adopción de medidas contra el asesinato de mujeres y niñas por razones de género», párrs. 1-19 (UN Doc. A/RES/70/176). 
violencia contra la mujer, incluidos los «crímenes de honor», que establezca de forma clara la obligación de los Estados de actuar con la diligencia debida para poner fin a este tipo de delitos ${ }^{60}$. En efecto, como se señala en el Informe de la Relatora Especial sobre la violencia contra la mujer, sus causas y consecuencias, de 29 de julio de 2015, aunque en el sistema de derechos humanos de las Naciones Unidas la violencia contra la mujer en sus distintas manifestaciones está cubierta por un conjunto de tratados, resoluciones, recomendaciones y declaraciones, sin embargo, no hay un único y exclusivo instrumento jurídicamente vinculante que establezca todas las formas de violencia contra la mujer como una violación de los derechos humanos específica, grave y generalizada, proponiéndose la adopción de un instrumento internacional específico y vinculante que ofrezca un marco normativo claro y obligue de una forma fehaciente a los Estados mediante un sistema de rendición de cuentas al cumplimiento de sus obligaciones en materia de violencia contra la mujer, incluida su manifestación más extrema como son los «crímenes de honor» ${ }^{61}$. Así, un Convenio internacional específico sobre la eliminación de la violencia contra la mujer garantizaría que se pudiese exigir a los Estados el cumplimiento de unas normas vinculantes desde el punto de vista jurídico, constitutivas de un marco normativo nítido para la protección de mujeres y niñas a escala mundial, contando además con un órgano especial de supervisión que se encargaría de analizar en profundidad la evolución de la situación tanto a nivel global como nacional ${ }^{62}$.

Desde este planteamiento, en una adenda al informe de la Relatora Especial se incluye un Proyecto de Convención para la Eliminación de la Violencia contra

60. En el informe de la Relatora Especial de 2014 ya se hace referencia a la ausencia de un instrumento jurídicamente vinculante en materia de violencia contra la mujer, «La Relatora Especial ha señalado la existencia de un vacío normativo a nivel internacional. La ausencia de un instrumento jurídicamente vinculante en materia de violencia contra la mujer impide que esta cuestión se plantee como una violación de los derechos humanos propiamente dicha, que comprenda de forma genérica todas las manifestaciones de violencia contra las mujeres y que recoja con toda claridad la obligación de los Estados de actuar con la diligencia debida para poner fin a esta clase de violencia», ONU, Asamblea General, Informe de la Relatora Especial sobre la violencia contra la mujer, sus causas y sus consecuencias, Sra. Rashida Manjoo, presentado de conformidad con la Resolución 67/144 de la Asamblea, de 1 de septiembre de 2014, párr. 59 (UN Doc. A/69/368).

61. ONU, Asamblea General, Informe de la Relatora Especial sobre la violencia contra la mujer, sus causas y sus consecuencias, Sra. Rashida Manjoo, presentado de conformidad con la Resolución 69/147 de la Asamblea, de 29 de julio de 2015, párr. 66 (UN Doc. A/70/209).

62. ONU, Asamblea General, Informe de la Relatora Especial sobre la violencia contra la mujer, sus causas y sus consecuencias, Sra. Rashida Manjoo, presentado de conformidad con la Resolución 67/144 de la Asamblea, de 1 de septiembre de 2014, párr. 71 (UN Doc. A/69/368).

Feminismo/s 28, diciembre 2016, pp. 91-132 
las Mujeres y las Niñas ${ }^{63}$, contemplándose de forma expresa que los Estados deben velar porque no se considere la cultura, las costumbres, la religión, la tradición o el llamado «honor» una justificación de ningún acto de violencia cubierto por el ámbito de aplicación del Convenio. Asimismo, se establece que los Estados deben adoptar las medidas legislativas o de otro tipo necesarias para garantizar que, en los procedimientos penales abiertos por la comisión de uno de los actos de violencia incluidos en el ámbito de aplicación de la Convención, no se admita la cultura, las costumbres, la religión, la tradición o el supuesto «honor» como justificación de dichos actos, impidiéndose alegaciones según las cuales la víctima habría transgredido las normas o costumbres culturales, religiosas, sociales o tradicionales relativas a un comportamiento apropiado. Incluso, como en muchos de estos casos los actos de violencia contra las mujeres en nombre del supuesto «honor» se comenten a menudo por un menor, instigado por un miembro adulto de la familia, para evitar así la responsabilidad penal, en el Proyecto de Convención se obliga también a los Estados a adoptar las medidas legislativas necesarias para que la incitación hecha por cualquier persona adulta a un menor para que cometa tales actos no disminuya la correspondiente responsabilidad penal de esa persona en relación con los actos cometidos ${ }^{64}$.

Por todo, de llegar a aprobarse, la futura Convención de las Naciones Unidas para la Eliminación de la Violencia contra las Mujeres y las Niñas supondrá un aldabonazo importante para que los Estados dejen de admitir la cultura y la religión como justificación de los «crímenes de honor», contribuyéndose así a la efectiva erradicación de una de las manifestaciones más extremas de la violencia ejercida contra miles de mujeres en países de todo el mundo.

63. El Proyecto de Convención para la Eliminación de la Violencia contra las Mujeres y las Niñas se ha elaborado en el marco de un extenso proceso llevado a cabo desde 2012 por los Profesores Jackie Jones y Noelle Quenivet de la University of the West of England (UWE), en el que han participado diversos expertos y que se basa en instrumentos internacionales, como la Convención sobre la Eliminación de todas las Formas de Discriminación contra la mujer, así como en instrumentos regionales como el Convenio del Consejo de Europa sobre Prevención y Lucha contra la Violencia contra la Mujer y la Violencia Doméstica, la Convención Interamericana para Prevenir, Sancionar y Erradicar la Violencia contra la Mujer «Convención de Belem do Para» y el Protocolo a la Carta Africana de Derechos Humanos y de los Pueblos sobre los Derechos de la Mujer en Africa, ver UN, General Assembly, Human Rights Council, Addendum to the Human Right Council Thematic report of the Special Rapporteur on Violence, its Causes and Consequences, 16 June 2015, pp. 5-22 (UN Doc. A/HRC/29/27/Add.4).

64. UN, General Assembly, Human Rights Council, Addendum to the Human Right Council Thematic report of the Special Rapporteur on Violence, its Causes and Consequences, 16 June 2015, pp. 12 y 18 (A/HRC/29/27/Add.4). 


\section{REFERENCIAS BIBLIOGRÁFICAS}

Amnesty International. Reservations to the Convention on the Elimination of All Forms of Discrimination against Women -Weakening the protection of women from violence in the Middle East and North Africa region. 2004 [Publicación en línea], <https://unispal.un.org/DPA/DPR/unispal.nsf/0/58DC72B3A727CB13 85256F43005430CE>, consultado el 12-05-2016.

An-Na 'im, Abdullahi A. «State Responsibility Under International Human Rights Law to Change Religious and Customary Laws». Human Rights of Women: National and International Perspectives. Ed. Rebecca J. Cook. Philadelphia: University of Pennsylvania Press, 1994, 167-188.

Chesler, Phyllis. «Worldwide Trends in Honor Killings». Middle East Quarterly 17.2 (2010): 3-11.

Clark, Belinda. «The Vienna Convention Reservations Regimen and the Convention on Discrimination against Women». The American Journal of International Law 85.2 (1991): 281-321.

Cook, Rebbeca J. «Reservations to the Convention on the Elimination of All Forms of Discrimination Against Women». Virginia Journal of International Law 30 (1990): 643-709.

Freeman, Marsha A., Beate Rudolf y Christine Chinkin. The UN Convention on the Elimination of All Forms of Discrimination against Women: A Commentary. Oxford, New York: Oxford University Press, 2012.

Greiff, Shaina. «No justice in Justifications: Violence against Women in the Name of Culture, Religion, and Tradition». The Global Campaing to Stop Killing and Stoning Women. 2010 <http://citeseerx.ist.psu.edu/viewdoc/download?doi= 10.1.1.186.3212\&rep=repl\&type=pdf $>$, consultado el 12-05-2016.

Holtmaat, Rikki y Jonneke Naber. Women's Human Rights and Culture; from Deadlock to Dialogue. Portland: Intersentia, 2011.

Kusha, Hamid R. y Nawal H. Ammar. «Stoning Women in the Islamic Republic of Iran: Is it Holy Law or Gender Violence». Arts and Social Sciences Journal 5.1 (2014): 1-9 <http://www.omicsonline.com/open-access/stoning-women-in-the-islamicrepublic-of-iran-is-it-holy-law-or-gender-violence-2151-6200.1000063.pdf> consultado el 22-04-2016.

Kogacioglu, Dicle. «The Tradition effect: Framing honor crimes in Turkey», Differences: A Journal of Feminist Cultural Studies 15. 2 (2004): 119-151.

Koukoulis-Spiliotopoulos, Sophia. «The limits of Cultural Traditions», Annuaire International des Droits de l'Homme, 3 (2008): 411-433.

Nyamu, Celestine I. «How Should Human Rights and Development Respond to Cultural Legitimization of Gender Hierarchy in Developing Countries?» Harvard International Law Journal 41 (2000): 381-418.

Raday, Frances. «Culture, Religion and Gender». International Journal of Constitutional Law 1. 4 (2003): 663-715. 
Raday, Frances. "Culture, Religion and CEDAW's art 5(a)». The Circle of Empowerment: 25 Years of the UN Committee on the Elimination of Discrimination against Women. Eds. B. Schöpp-Schilling, Hanna Beate, Cees Flinterman. New York: The Feminist Press, 2007, 67-85.

Terman, Rochelle L. «To Specify or Single Out: Should We Use the Term "Honor Killing"?». Muslim World Journal of Human Rights 7.1 (2010): 1-41.

United Nations. Supplement to the Handbook for Legislation on Violence against Women. «Harmful practices» against women. New York: Department of Economic and Social Affairs, Division for the Advancement of Women, $2011<\mathrm{http} / / / \mathrm{www}$. un.org/womenwatch/daw/vaw/handbook/Supplement-to-Handbook-English. pdf>, consultado el 22-04-2016.

United Nations. Office on Drugs and Crime (UNODC). Recommendations for action against gender-related killing of women and girls. New York: United Nations Office on Drugs and Crime, $2015<\mathrm{http} / / / \mathrm{www} 2 . u n w o m e n . o r g / \sim$ media/headquarters/attachments/sections/library/publications/2015/genderrelated_killing.pdf? $\mathrm{v}=1 \& d=20151026 \mathrm{~T} 163328>$, consultado el 22-04-2016.

United Nations Population Fund (UNFPA). The State of World Population 2000. Lives Together, Worlds Apart: Men and Women in a time of Change. New York: United Nations Population Fund, $2000<$ http://www.unfpa.org/sites/default/ files/pub-pdf/swp2000_esp.pdf>, consultado el 22-04-2016.

United Nations. Report of the expert group meeting on good practices in legislation on violence against women. United Nations Division for the Advancement of Women. United Nations Office on Drugs and Crime. Viena, 2008 $<$ http://www.un.org/womenwatch/daw/egm/vaw_legislation_2008/Report\%20 EGMGPLVAW\%20(final\%2011.11.08).pdf>, consultado el 22-04-2016.

Velázquez Borges, Sudis María. «Las reservas a la Convención sobre la eliminación de todas las formas de discriminación contra la mujer». Revista Facultad de Derecho y Ciencias Políticas 41. 115 (2011): 427-449.

Welchman, Lynn y Sara Hossain. «Honour»: Crimes, paradigms, and violence against women. London: Zed Books, 2005.

Winter, Bronwyn, Denise Thompson y Sheila Jeffreys. «The UN Approach to Harmful Traditional Practices». International Feminist Journal Politics 4.1 (2002): 72-94.

Wyttenbach, Judith. «Violence against Women, Culture/Religious Tradition and the International Standard of Due Diligence», Due Diligence and its Application to Protect Women from Violence. Ed. Carin Benninger-Budel. Leiden: Martinus Nijhoff Publishers, 2008, 225-239.

Zechenter, Elizabeth M. «In the Name of Culture: Cultural Relativism and the Abuse of the Individual». Journal of Anthropological Research 53.3 (1997): 319-347. 